\title{
Understanding the functional neuroanatomy of acquired prosopagnosia
}

Citation for published version (APA):

Sorger, B., Goebel, R. W., Schiltz, C., \& Rossion, B. (2007). Understanding the functional neuroanatomy of acquired prosopagnosia. Neuroimage, 35(2), 836-52. https://doi.org/10.1016/j.neuroimage.2006.09.051

Document status and date:

Published: 01/01/2007

DOI:

10.1016/j.neuroimage.2006.09.051

Document Version:

Publisher's PDF, also known as Version of record

Document license:

Taverne

Please check the document version of this publication:

- A submitted manuscript is the version of the article upon submission and before peer-review. There can be important differences between the submitted version and the official published version of record.

People interested in the research are advised to contact the author for the final version of the publication, or visit the DOI to the publisher's website.

- The final author version and the galley proof are versions of the publication after peer review.

- The final published version features the final layout of the paper including the volume, issue and page numbers.

Link to publication

\footnotetext{
General rights rights.

- You may freely distribute the URL identifying the publication in the public portal. please follow below link for the End User Agreement:

www.umlib.nl/taverne-license

Take down policy

If you believe that this document breaches copyright please contact us at:

repository@maastrichtuniversity.nl

providing details and we will investigate your claim.
}

Copyright and moral rights for the publications made accessible in the public portal are retained by the authors and/or other copyright owners and it is a condition of accessing publications that users recognise and abide by the legal requirements associated with these

- Users may download and print one copy of any publication from the public portal for the purpose of private study or research.

- You may not further distribute the material or use it for any profit-making activity or commercial gain

If the publication is distributed under the terms of Article $25 \mathrm{fa}$ of the Dutch Copyright Act, indicated by the "Taverne" license above, 


\title{
Understanding the functional neuroanatomy of acquired prosopagnosia
}

\author{
Bettina Sorger, ${ }^{\mathrm{a}, \mathrm{b}, *}$ Rainer Goebel, ${ }^{\mathrm{a}, \mathrm{b}, \mathrm{d}}$ Christine Schiltz, ${ }^{\mathrm{c}}$ and Bruno Rossion ${ }^{\mathrm{c}, *}$ \\ ${ }^{a}$ Department of Cognitive Neuroscience, Maastricht University, The Netherlands \\ ${ }^{\mathrm{b}}$ Maastricht Brain Imaging Center (M-BIC), Maastricht, The Netherlands \\ ${ }^{\mathrm{c}}$ Unité Cognition and Développement and Laboratoire de Neurophysiologie, Université catholique de Louvain, Belgium \\ ${ }^{\mathrm{d}}$ F.C. Donders Centre for Cognitive Neuroimaging, Nijmegen, The Netherlands
}

Received 29 May 2006; revised 26 September 2006; accepted 27 September 2006

Available online 14 February 2007

One of the most remarkable disorders following brain damage is prosopagnosia, the inability to recognize faces. While a number of cases of prosopagnosia have been described at the behavioral level, the functional neuroanatomy of this face recognition impairment, and thus the brain regions critically involved in normal face recognition, has never been specified in great detail. Here, we used anatomical and functional magnetic resonance imaging (fMRI) to present the detailed functional neuroanatomy of a single case of acquired prosopagnosia (PS; Rossion, B., Caldara, R., Seghier, M., Schuller, A.-M., Lazeyras, F., Mayer, E., 2003a. A network of occipito-temporal face-sensitive areas besides the right middle fusiform gyrus is necessary for normal face processing. Brain 126, 2381-95; Rossion, B., Joyce, C.A., Cottrell, G.W., Tarr, M.J., 2003b. Early lateralization and orientation tuning for face, word, and object processing in the visual cortex. Neuroimage 20, 1609-24) with normal object recognition. First, we clarify the exact anatomical location and extent of PS' lesions in relation to (a) retinotopic cortex, (b) face-preferring regions, and (c) other classical visual regions. PS' main lesion - most likely causing her prosopagnosia - is localized in the posterior part of the right ventral occipitotemporal cortex. This lesion causes a left

Abbreviations: BA(s), Brodmann area(s); BFRT, Benton Face Recognition Test; BOLD, blood oxygenation level-dependent; BORB, Birmingham Object Recognition Battery; EPI, echo-planar imaging; 'FFA', 'fusiform face area'; (f)MRI, (functional) magnetic resonance imaging; hMT+/V5, human middle temporal cortex; LOC, lateral occipital complex (dLOCdorsal, vLOC - ventral); MFG, middle fusiform gyrus; MTG, middle temporal gyrus; 'OFA', 'occipital face area'; PET, position emission tomography; 'PPA', 'parahippocampal place area'; PFC, prefrontal cortex; ROI(s), region(s) of interest; STS, superior temporal sulcus; 'VWFA', 'visual word form area'; WRMT, Warrington Recognition Memory Test.

* Corresponding authors. B. Sorger is to be contacted at Department of Cognitive Neuroscience, Faculty of Psychology, Maastricht University, Postbus 616, 6200 MD Maastricht, The Netherlands. Fax: +31 433884125. B. Rossion, Unité Cognition and Développement and Laboratoire de Neurophysiologie, Université catholique de Louvain, 10 Place cardinal Mercier, 1348 Louvain-la-Neuve, Belgium. Fax: +32 10473774 .

E-mail addresses: b.sorger@psychology.unimaas.nl (B. Sorger), bruno.rossion@psp.ucl.ac.be (B. Rossion).

Available online on ScienceDirect (www.sciencedirect.com). superior paracentral scotoma, as frequently observed in cases of prosopagnosia.

While the borders of the early visual areas in the left hemisphere could be delineated well, the extensive posterior right-sided lesion hampered a full specification of the cortical representation of the left visual field. Using multiple scanning runs, face-preferring activation was detected within the right middle fusiform gyrus (MFG) in the socalled 'fusiform face area' ('FFA'), but also in the left inferior occipital gyrus (left 'OFA'), and in the right posterior superior temporal sulcus (STS). The dorsal part of the lateral occipital complex (LOC) and the human middle temporal cortex (hMT+/V5) were localized bilaterally. The color-preferring region $\mathrm{V} 4 / \mathrm{V8}$ was localized only in the left hemisphere. In the right hemisphere, the posterior lesion spared the ventral part of $L O C$, a region that may be critical for the preserved object recognition abilities of the patient, and the restriction of her deficit to the category of faces. The presumptive functions of both structurally damaged and preserved regions are discussed and new hypotheses regarding the impaired and preserved abilities of the patient during face and non-face object processing are derived.

Fine-grained neurofunctional analyses of brain-damaged single cases with isolated recognition deficits may considerably improve our knowledge of the brain regions critically involved in specific visual functions, such as face recognition.

(C) 2006 Elsevier Inc. All rights reserved.

Keywords: Prosopagnosia; Face recognition; Object recognition; Motion perception; Color perception; Visual cortex; Retinotopy; Functional magnetic resonance imaging; Perimetry

\section{Introduction}

Prosopagnosia is defined as the inability to recognize individual faces, usually following brain damage, despite intact intellectual and cognitive function and preserved low-level visual processing. The condition of this spectacular impairment was firstly described in the 19th century (Quaglino et al., 1867; Wilbrand, 1892; Wigan, 1944) and introduced as a term by Bodamer in 1947 (Ellis and Florence, 1990). Despite the relative rarity of this disorder, several detailed 
studies of prosopagnosic patients have been reported in the literature in the 1970s and 1980s, aiming at correlating clinical aspects and the localization of the lesions causing this face recognition impairment (e.g., Lhermitte et al., 1972; Meadows, 1974; Benton, 1980; Damasio et al., 1982). However, more recent case studies of acquired prosopagnosia (e.g., Schweich and Bruyer, 1993; Farah et al., 1995; Clarke et al., 1997; Henke et al., 1998; Gauthier et al., 1999; Dixon et al., 1998; Barton et al., 2002; 2004; Joubert et al., 2003; Bukach et al., 2006) have concentrated exclusively on the behavioral aspects of the deficit. For instance, the double dissociation reported between the recognition of facial expression and facial identity (e.g., Bruyer et al., 1983; Tranel et al., 1988), or lipreading and face recognition (Campbell et al., 1986), has helped to distinguish between different face processing sub-functions in a cognitive model of face processing (Bruce and Young, 1986). Other studies have tested prosopagnosic patients to address the question of the interaction between semantic and visual features during face recognition (Dixon et al., 1998), to determine which facial cues can no longer be processed efficiently in such cases (Caldara et al., 2005; Bukach et al., 2006) or to document the functional distinction between configural and featural processing of faces (e.g., Boutsen and Humphreys, 2002; Barton et al., 2002; Joubert et al., 2003; Sergent and Signoret, 1992). Perhaps most significantly, the study of acquired prosopagnosia at the functional level has largely contributed to the theoretical debate about the modularity of face processing (e.g., see Barton and Cherkasova, 2005; Farah et al., 1995; Gauthier et al., 1999; Henke et al., 1998; Sergent and Signoret, 1992).

The shift of interest from a neuroanatomo-clinical perspective to a cognitive approach of face processing impairments in the literature coincides with the advent of functional neuroimaging studies of face processing in the healthy human brain, initiated by Justine Sergent and her colleagues in the early 1990s (Sergent et al., 1992, 1994). These and subsequent studies have led to a relatively precise mapping of the cortical network of brain regions involved in normal face processing in humans (for a review, see Haxby et al., 2000). Because neuroimaging in healthy subjects alone is unable to indicate whether the regions activated during face processing are critical for the successful perception and recognition of faces, the precise identification of the lesions causing prosopagnosia is still in principle of great interest to understand the neural basis of face processing. However, using only the lesion method (i.e., correlating neuroanatomical and clinical outcomes) as a means to establish the neuroanatomical basis of prosopagnosia is associated with a number of weaknesses (e.g., Sergent et al., 1992). First, even though the critical regions underlying a face perception deficit are thought to encompass the lingual, fusiform, and parahippocampal gyri with a right-hemisphere dominance, there is a large amount of variability in terms of the extent and the location of the lesions among prosopagnosic patients (Bouvier and Engel, 2006; Barton et al., 2002; Sergent and Signoret, 1992; Damasio et al., 1982; Meadows, 1974). Second, brain regions which may appear structurally intact and thus not considered to be critically associated with the impaired function(s) in a patient may in fact be functionally depressed because they do not receive normal inputs from lesioned regions. For instance, Sergent and Signoret (1992) reported a case of prosopagnosia with no structural damage to the right parahippocampal gyrus. Yet, this region was functionally depressed, as observed with positron emission tomography (PET), most likely because it was deprived of normal inputs from lesioned parts of the cortex (see also Michel et al., 1989). Third, the prosopagnosic disorder is generally associated with important perceptual deficits (Barton et al., 2004), most notably color processing (central achromatopsia, see Bouvier and Engel, 2006; Zeki, 1990; Damasio et al., 1980; Meadows, 1974), and object recognition impairments (e.g., Clarke et al., 1997; Damasio et al., 1982; Levine and Calvanio, 1989; Gauthier et al., 1999), hampering the precise correlation of the lesions' location with the functional face recognition impairments. These limitations of neuroanatomo-clinical correlation studies based on structural imaging alone, coupled with the rarity of the prosopagnosic deficit, may explain why the lesions leading to face processing impairments have not yet been specified with great accuracy. In fact, the precise localization of the lesioned regions with respect to particular gyri and sulci to retinotopic cortical areas and to other functionally defined higher visual regions is still lacking in the current literature.

Taking these issues into account, in the present paper we report a detailed neuroanatomical and neurofunctional analysis of a single case of prosopagnosia, PS, a patient presenting a deficit restricted to the recognition of individual faces following brain damage. Our first goal was to help clarify the neural basis of face recognition impairments in general. Our second objective was aimed at complementing previous data collected on this pure case of prosopagnosia (Rossion et al., 2003a; Caldara et al., 2005; Schiltz et al., 2006) to provide information about the functional and neuroanatomical aspects of her face recognition impairment. Clarifying in detail the functional neuroanatomy of the visual system of this patient may contribute to a better understanding of the nature of the identified deficits and generate new hypotheses regarding the impaired and preserved abilities of the patient during face and non-face object processing.

The prosopagnosic patient PS investigated in the present study is of particular interest because she presents a massive impairment at recognizing faces and yet has largely preserved low-level vision and intact object recognition abilities (Rossion et al., 2003a; Schiltz et al., 2006). Structural magnetic resonance imaging (MRI) of PS revealed lesions to the left middle ventral cortex (mainly fusiform gyrus) and the right inferior occipital cortex but displayed a structurally intact right middle fusiform gyrus (MFG). In our previous functional MRI (fMRI) experiments, we disclosed a preferential activation to faces as compared to objects in the right MFG ('fusiform face area', 'FFA', Kanwisher et al., 1997) of the patient (Rossion et al., 2003a; Schiltz et al., 2006).

In the present report, we complement these findings by defining precisely (a) the neuroanatomical basis of her face recognition impairments, i.e., the locations and the extent of her lesions with respect to well-known human gyri and sulci as well as to the functionally mapped retinotopic cortex, and (b) the functional neuroanatomy of the visual cortex, in particular relative to the regions involved in face and object perception. More precisely, we identify the exact anatomical locations of the patient's lesions in relation to: (1) early retinotopic visual areas (e.g., Engel et al., 1994), (2) facepreferring $^{1}$ visual brain regions in the fusiform gyrus ('FFA'; Kanwisher et al., 1997), the occipital cortex ('occipital face area', 'OFA'; Gauthier et al., 2000), and in the posterior part of the superior temporal sulcus (STS; e.g., Puce et al., 1998), and (3) nonface-preferring higher visual brain regions, i.e., object-preferring lateral occipital complex (LOC; Malach et al., 1995), house-/placepreferring 'parahippocampal place area' ('PPA'; Epstein and

\footnotetext{
1 We will use the (admittedly animistic) expression "face-preferring" rather than "face-sensitive" or "face-specific" because there are many facesensitive brain regions (e.g., LOC, even hMT+/V5), and no region responding exclusively to faces has been found so far.
} 
Kanwisher, 1998), motion-preferring human middle temporal cortex (hMT+/V5; Zeki et al., 1991), and the color-preferring area V4/V8 (Hadjikhani et al., 1998). The importance of such a neurofunctional ${ }^{2}$ (vs. merely neuroanatomical) lesions' definition is reinforced by the high inter-individual variability of the location of high-level visual regions (Culham and Kanwisher, 2001).

\section{Material and methods}

Subjects

Patient PS

PS' clinical history and functional deficits have already been described in detail (see Rossion et al., 2003a) and will be therefore only briefly summarized here. PS is a 56 years old (born in 1950) woman working as a kindergarten teacher, who sustained a closed head injury in 1992. Conventional MRI revealed extensive lesions of the left mid-ventral (mainly fusiform gyrus) and the right inferior occipital cortex. Furthermore, a minor damage to the left posterior cerebellum was localized. Despite these multiple, partially extensive brain lesions and the initial pronounced cognitive deficits following the accident, PS recovered extremely well after medical treatment and neuropsychological rehabilitation (Mayer et al., 1999; Mayer and Rossion, in press). Her only continuing complaint remains a profound difficulty in recognizing faces, including those of her family as well as her own face. To determine a person's identity, she usually relies on contextual information and non-face cues such as the person's voice, posture, or gait, etc. But she may also use suboptimal facial cues such as the mouth or the external contour of the face (Caldara et al., 2005). The Benton Face Recognition Test (BFRT, Benton and van Allen, 1972) ranks her as highly impaired (score: 27/54) and the Warrington Recognition Memory Test (WRMT; Warrington, 1984) for faces characterizes her as significantly less accurate than controls (score: 18/25). PS does not present any difficulty in recognizing objects, even at a subordinate level (Rossion et al., 2003a; Schiltz et al., 2006). PS' visual field is almost full (small left paracentral scotoma), and her visual acuity is good (0.8 for both eyes as tested in August 2003). The performance of PS on standard clinical and neuropsychological tests of visual perception and recognition is summarized in Table 1.

\section{Control participants}

In addition to PS, two sex-matched healthy volunteers (BS and CG [34 and 37 years old], normal vision) participated in the neuroimaging experiments. Normal subjects were tested only for illustration of the locations of the regions of activation in the normal brain, not for direct comparisons (i.e., of fMRI signal magnitudes) with the patient (see Rossion et al., 2003a; Schiltz et al., 2006). Younger control subjects were chosen mainly for practical reasons. It should be noted that there is no evidence for age-related differences of brain activation at least for the face-preferring regions investigated here (e.g., Brodtmann et al., 2003; Schiltz et al., 2006).

PS as well as the control participants gave their informed written consent prior to the fMRI experiments. The study was conducted in conformity to the Declaration of Helsinki and was approved by the Ethics Committee of the Medical Department of the University of Louvain. The subjects' handedness was evaluated by the Edinburgh Inventory (Oldfield, 1971). All subjects were strongly right-handed.

\footnotetext{
${ }^{2}$ In this paper, the term 'neurofunctional' refers to functional imaging studies.
}

\section{Perimetry}

The patient's visual fields were mapped using a combination of dynamic and static perimetry. PS was seated at a Tübingen perimeter (Oculus, Wetzlar, FRG), and fixated a central 30' red spot. Fixation was controlled by means of an infrared sensitive video camera projecting an enlarged image of the tested eye onto a video screen positioned in the experimenter's field of view. The two eyes were tested separately, with the untested eye covered by a patch. On a low photopic white background $\left(10 \mathrm{~cd} / \mathrm{m}^{2}\right)$, a circular white $116^{\prime}$ target of $320 \mathrm{~cd} / \mathrm{m}^{2}$ luminance was moved slowly from the periphery towards fixation, or from unseeing regions (such as the blind spot) towards the normal field. The patient was asked to press a bell button whenever the stimulus appeared in her field of view. In addition to mapping the borders at closely spaced positions in the central portion of the field out to $30^{\circ}$ eccentricity, the same stimulus was presented for $200 \mathrm{~ms}$ to further delineate small defective regions within the field. Again, PS pressed the bell button whenever she detected the briefly presented stimulus.

\section{Additional tests of low-level vision}

\section{Color perception/discrimination}

PS was tested before (Rossion et al., 2003a) with the Ishihara plates, commonly used to test achromatopsics, and she scored in the lower range ( 5 mistakes) in this task which requires to segregate isoluminant colored circles to identify the letters they form. Here we complement this information by reporting the Farnsworth-Munsell 100-Hue test (Farnsworth, 1957), which requires to arrange colored disks that continuously vary in hue. This test is commonly used to assess color deficits (see Bouvier and Engel, 2006), and cerebral achromats perform at chance levels (e.g., Heywood et al., 1996). The worst performing $5 \%$ of the normal population score between 80 and 195 depending upon age (for normative data see Kinnear and Sahraie, 2002).

\section{Stimuli, designs, and tasks of the fMRI experiments}

\section{Retinotopic mapping experiments}

The responsiveness and delineation of the early visual areas V1, $\mathrm{V} 2, \mathrm{~V} 3, \mathrm{VP}, \mathrm{V} 3 \mathrm{~A}$, and V4v - the terminology of the early visual areas used here follows that of Felleman and Van Essen (1991) were investigated with retinotopic mapping scans (cf. Sereno et al., 1995; Goebel et al., 2003). For eccentricity mapping, a ring-shaped configuration of black and white contrast-reversing $(8 \mathrm{~Hz})$ checkers was presented centered around an orange-colored fixation point. The ring started with a radius of approximately $1^{\circ}$ visual angle and expanded to a radius of $12^{\circ}$ within $96 \mathrm{~s}$. For polar angle mapping, the same pattern was configured as a wedge subtending $22.5^{\circ}$ in polar angle with the tip at the fixation point. The wedge started at the left horizontal meridian and rotated clockwise for a full cycle of $360^{\circ}$ within $96 \mathrm{~s}$. Each retinotopic mapping experiment consisted of eight repetitions of full expansions and full rotations, respectively. The subjects were instructed to look at the fixation point while attentively recognizing the changing location of the stimulus presented.

\section{Motion perception experiment}

Motion-preferring cortex was identified by comparing the hemodynamic responses during presentation of a moving stimulus (moving plaids) and a stationary control stimulus (static plaids). The 
Table 1

Results of PS' ophthalmologic and neuropsychological examination

\begin{tabular}{|c|c|}
\hline \multicolumn{2}{|l|}{ A. Basic/perceptual visual processing } \\
\hline Acuity & 0.8 (bilaterally) \\
\hline \multicolumn{2}{|l|}{ Contrast sensitivity } \\
\hline - Contrast sensitivity test (Nicolet) & $\mathrm{OK}$ \\
\hline \multicolumn{2}{|l|}{ Color perception/discrimination } \\
\hline • Ishihara plates & 12/17 (lower range) \\
\hline - Farnsworth-Munsell 100-Hue test & 145 (lower range) \\
\hline \multicolumn{2}{|l|}{ B. Low-level visual processing } \\
\hline Benton line orientation & $\mathrm{OK}$ \\
\hline BORB: Object copying (test 1 ) & OK \\
\hline BORB: Line length (test 2) & OK \\
\hline BORB: Size (test 3) & $\mathrm{OK}$ \\
\hline BORB: Orientation (test 4) & OK \\
\hline BORB: Gap position (test 5 ) & $\mathrm{OK}$ \\
\hline BORB: Overlapping shapes (test 6) & OK (slowed for 3 subtests) \\
\hline BORB: Minimal feature match (test 7) & OK \\
\hline BORB: Foreshortened views (test 8) & $\mathrm{OK}$ \\
\hline \multicolumn{2}{|l|}{ C. Visual object recognition } \\
\hline BORB: Object decision task (test 10) & $\mathrm{OK}$ \\
\hline $\begin{array}{l}\text { BORB: Item match (class recognition, } \\
\text { test } 11 \text { ) }\end{array}$ & OK \\
\hline BORB: Semantic association (test 12) & OK \\
\hline Object decision task (computer-aided) & $\begin{array}{l}\text { OK (objects: } 946 \mathrm{~ms} \text {, } \\
\text { non-objects: } 1626 \mathrm{~ms} \text { ) }\end{array}$ \\
\hline $\begin{array}{l}\text { Object naming (colorized Snodgrass and } \\
\text { Vanderwart [1980] drawings by Rossion } \\
\text { and Pourtois [2004]) }\end{array}$ & OK \\
\hline \multicolumn{2}{|l|}{ D. Short term visual memory } \\
\hline Test de la ruche (French) & $\mathrm{OK}$ \\
\hline \multicolumn{2}{|l|}{ E. Long term visual memory } \\
\hline Doors test & $\mathrm{OK}$ \\
\hline Rey complex drawing & $\mathrm{OK}$ \\
\hline \multicolumn{2}{|l|}{ F. Visual face processing } \\
\hline BFRT & 27/54 (strongly impaired) \\
\hline WRMT for faces & 18/25 (impaired, percentile 3) \\
\hline \multicolumn{2}{|l|}{ G. Reading } \\
\hline Reading & $\begin{array}{l}\text { OK (slightly slowed down, } \\
\text { as tested in June 2005) }\end{array}$ \\
\hline \multicolumn{2}{|l|}{ H. Visual imagery } \\
\hline BORB: Object drawings (test 9) & OK \\
\hline \multicolumn{2}{|l|}{ I. Reaction time } \\
\hline Phasic alert & Slow, percentile 5 \\
\hline
\end{tabular}

Table adapted from Rossion et al., 2003a.

monochrome stimuli were generated using the Direct $\mathrm{X}$ graphics library (see Castelo-Branco et al., 2002). The moving stimuli consisted of two square-wave gratings moving in opposite directions with a velocity of $8 \% \mathrm{~s}$ in a circular aperture. The static control stimulus was composed of two overlaid square-wave gratings. Each stimulation block lasted for $20 \mathrm{~s}$ and was repeated ten times within the whole functional run. The two experimental conditions were interchangeably presented. Subjects were instructed to pay attention to the stimuli throughout the whole experiment.

\section{Color perception experiment}

In order to define color-preferring regions, brain responses to color and gray-scale perception were compared. During each of the (six colored, six gray-scale) stimulation blocks, 24 pictures of $750 \mathrm{~ms}$ duration were shown resulting in a block length of $18 \mathrm{~s}$. The color stimuli were colored patterns made up of a set of small rectangles of different physically isoluminant colors and sizes. The gray-scale versions of the pictures had comparable saturation and intensity but with no variation in hue. The two experimental conditions were interchangeably presented and separated by a fixation period of $9 \mathrm{~s}$. The task of the subject was to look attentively at the stimuli while fixating on the small cross, which was centered in the visual scene.

\section{Higher level vision experiments}

Localization of face-preferring regions. The stimuli, experimental design, and task were the same as used by Rossion et al., 2003a. In a block design, epochs of face and object presentations (18 s) were counterbalanced and separated by baseline epochs (fixation cross, $9 \mathrm{~s}$ ). Within one functional run, each experimental condition was presented six times. In each epoch, 24 stimuli were presented for $750 \mathrm{~ms}$, without any offset, but a small shift of position (20 pixels). The subjects' task was to detect (and indicate by button press) an immediate repetition of the same face or object image (one-back matching task). Normal subjects performed two functional runs. In order to maximize the possibility to detect all face-preferring regions in PS by increasing the statistical power, we also used the data of identical experiments that had been performed previously and reported in Schiltz et al. (2006; 2 localizer runs). Thus, data of six functional runs (including 4 new face localizer recordings) were included in the statistical analysis.

Localization of object-preferring regions. According to the functional definition of object-preferring cortex (Malach et al., 1995), object photos and scrambled versions of these were presented using a block design alternating stimulation of $30 \mathrm{~s}$ (three object blocks and three scrambled object blocks, counterbalanced) and fixation periods of $20 \mathrm{~s}$ (seven blocks only presenting a small fixation cross on a black background). The scrambling of each photo was realized by tessellating the object images into little squares of $10 \times 10$ pixels. Within each stimulation block, 45 different photos $(252 \times 252$ pixel gray-scale images $)$ of common objects/scrambled objects were foveally presented with a duration of $666 \mathrm{~ms}$ per stimulus. The subject's task was to fixate and attentively follow the visual stimulation.

Localization of house-preferring regions. The design and the subject's task of this experiment were exactly the same as in the previous one (Localization of object-preferring regions). Only the content of the stimulation conditions had to be adjusted following Epstein and Kanwisher (1998). Accordingly, photographs of houses and faces were presented during the two experimental condition blocks.

Stimulus presentation in the scanner

All stimulus images were generated by a personal computer and projected onto a frosted screen located at the end of the scanner bore (at the side of the subjects' head) with a liquid crystal display (LCD) projector (SV-6011, Avotec, Inc., Stuart, USA [measurements in Brussels]; VPL-PX21, Sony, Tokyo, Japan [measurements in 
Nijmegen]; PLC-XT11, Sanyo North America Corporation, San Diego, USA [measurements in Maastricht]). The subjects viewed the stimuli via a mirror mounted to the head coil at an angle of $\sim 45^{\circ}$.

\section{Anatomical and functional MRI}

The MRI units used were commercial MRI scanners with magnetic field strengths of $1.5 \mathrm{~T}$ (Gyroscan Intera, Philips, Best, The Netherlands [measurements in Brussels]) and $3 \mathrm{~T}$ (Magnetom Trio, Siemens AG, Erlangen, Germany [measurements in Nijmegen]; Siemens Allegra, Siemens AG, Erlangen, Germany [measurements in Maastricht]) provided with standard quadrature birdcage head coils. Each subject underwent three MR sessions in total.

\section{Anatomical measurements}

At each session, one three-dimensional (3D) T1-weighted data set encompassing the whole brain was acquired for every subject after initial positioning images had been obtained. For precise anatomical reference, a magnetization-prepared rapid acquisition gradient echo (MPRAGE) sequence (scan parameters: repetition time $[\mathrm{TR}]=8.1 \mathrm{~ms}$, echo time $[\mathrm{TE}]=3.7 \mathrm{~ms}$, flip angle $[\mathrm{FA}]=8^{\circ}$, field of view $[\mathrm{FOV}]=256 \times 256 \mathrm{~mm}^{2}$, matrix size $=256 \times 256$, number of slices $=200$, slice thickness $=1 \mathrm{~mm}$, no gap, total scan time $=12 \mathrm{~min}$ and $49 \mathrm{~s}$ ) was used in one of the sessions. This sequence especially facilitates later cortex segmentation. In the remaining sessions, a faster MPRAGE sequence with differing scan parameters $\left(\mathrm{TR}=30 \mathrm{~ms}, \mathrm{TE}=4.6 \mathrm{~ms}, \mathrm{FA}=30^{\circ}, \mathrm{FOV}=220 \times\right.$ $220 \mathrm{~mm}^{2}$, matrix size $=256 \times 212$, number of slices $=110$, slice thickness $=1.5 \mathrm{~mm}$, no gap, total scan time $=9 \mathrm{~min}$ and $14 \mathrm{~s}$ ) was applied.

\section{Functional measurements}

In order to determine the functional regions of interest (ROIs), repeated single-shot echo-planar imaging (EPI) was performed using the blood oxygenation level-dependent (BOLD) effect as an indirect marker of local neuronal activity (Ogawa et al., 1990). The scan parameters of the functional sequence used were: $\mathrm{TE}=50 \mathrm{~ms}$, $\mathrm{FA}=90^{\circ}$, matrix size $=64 \times 64, \mathrm{FOV}=250 \times 250 \mathrm{~mm}^{2}$, slice order $=$ descending, interleaved. Information about the other scan parameters (TR, number of slices, slice thickness etc.), which varied over the different experiments, is provided in Table 2.

\section{Analysis of anatomical and functional data}

The analysis of the anatomical and functional data sets (exclusively single subject analysis) was performed using BrainVoyager QX (Version 1.6; Brain Innovation, Maastricht, The Netherlands).

Prior to the regression analysis, the functional data sets were subjected to a series of preprocessing operations. To exclude scanner-related signal drifts, a linear trend removal was performed. Temporal high-pass filtering was applied to remove temporal frequencies lower than 3 cycles per run. Small interscan head movements, which altogether not exceeded a translation of $3 \mathrm{~mm}$ or a rotation of $3^{\circ}$, were corrected for by a rigid body algorithm rotating and translating each functional volume in $3 \mathrm{D}$ space. To enable the comparison between subjects, all anatomical as well as the functional volumes were spatially normalized (Talairach transformation; Talairach and Tournoux, 1988). Subsequently, the functional data were analyzed using multiple regression models consisting of predictors, which corresponded to the particular experimental conditions of each experiment. Following Boynton et al. (1996), the predictor time courses used were generated on the basis of a linear model of the relation between neural activity and hemodynamic response. To compare the BOLD responses during the experimental conditions, general linear model (GLM) contrasts were computed resulting in t-maps. Signal differences with a threshold of $p<0.05$ (one-tailed, Bonferroni-corrected for multiple comparisons) were considered as significant. For each subject, the regions of interest were individually localized by appropriate contrasts for localizing (a) motion-preferring regions: moving plaids vs. static plaids; (b) color-preferring regions: colored vs. gray-scale patterns; (c) face-preferring regions: face pictures vs. object pictures; (d) object-preferring regions: object pictures vs. scrambled object pictures; (e) house-/place-preferring regions: house pictures vs. face pictures. Talairach coordinates (centers of gravity of the ROIs) were calculated for all relevant activation clusters.

Retinotopic maps were created based on a cross-correlation analysis (for details, see Linden et al., 1999; Goebel et al., 2003). The eccentricity and polar angle represented by a given cortical site were determined by finding the lag value maximizing the crosscorrelation. The obtained lag values at each voxel, corresponding to the eccentricity or polar angle of optimal stimulation, were encoded in pseudocolors. Voxels were included into the statistical map if the obtained cross-correlation coefficient $r$ was $>0.4 \quad(p<0.0001$,

Table 2

Scan parameters of the functional measurements varying over the experiments and subjects

\begin{tabular}{|c|c|c|c|c|c|c|c|}
\hline Experiment & $\begin{array}{l}\text { Areas/regions } \\
\text { to be defined }\end{array}$ & Place/field strength & $\begin{array}{l}\text { Number } \\
\text { of runs }\end{array}$ & $\begin{array}{l}\text { Number } \\
\text { of slices }\end{array}$ & Slice thickness & $\begin{array}{l}\text { Number } \\
\text { of volumes }\end{array}$ & TR (ms) \\
\hline $\begin{array}{l}\text { Retinotopic mapping } \\
\text { eccentricity mapping } \\
\text { polar mapping }\end{array}$ & $\mathrm{V} 1, \mathrm{~V} 2, \mathrm{~V} 3 \mathrm{~A}, \mathrm{VP}, \mathrm{V} 4 \mathrm{v}$ & $\begin{array}{l}\text { Brussels, } 1.5 \mathrm{~T} \text { (PS) } \\
\text { Nijmegen, } 3.0 \mathrm{~T}\end{array}$ & $\begin{array}{l}1 \\
1\end{array}$ & 28 & $3 \mathrm{~mm}$ & 268 & 2000 \\
\hline $\begin{array}{l}\text { Localization of face-preferring } \\
\text { regions }\end{array}$ & $\begin{array}{l}\text { 'FFA' } \\
\text { STS } \\
\text { 'OFA' }\end{array}$ & $\begin{array}{l}\text { Nijmegen, } 3.0 \mathrm{~T}(\mathrm{PS}) \\
\text { Maastricht, } 3.0 \mathrm{~T}\end{array}$ & 2 & 28 & $5 \mathrm{~mm}$ & 111 & 3000 \\
\hline \multirow[t]{4}{*}{$\begin{array}{l}\text { Localization of other classical } \\
\text { visual regions }\end{array}$} & $\mathrm{hMT}+/ \mathrm{V} 5$ & $\begin{array}{l}\text { Brussels, } 1.5 \mathrm{~T}(\mathrm{PS}) \\
\text { Nijmegen, } 3.0 \mathrm{~T}\end{array}$ & 1 & 28 & $4 \mathrm{~mm}$ & 200 & 2000 \\
\hline & LOC & $\begin{array}{l}\text { Brussels, } 1.5 \mathrm{~T} \\
\text { Nijmegen, } 3.0 \text { (CG) }\end{array}$ & 2 & 28 & $4 \mathrm{~mm}$ & 160 & 2000 \\
\hline & 'PPA' & $\begin{array}{l}\text { Brussels, } 1.5 \mathrm{~T} \text { (PS) } \\
\text { Nijmegen, 3.0 T }\end{array}$ & 2 & 28 & $4 \mathrm{~mm}$ & 160 & 2000 \\
\hline & $\mathrm{V} 4 / \mathrm{V} 8$ & $\begin{array}{l}\text { Nijmegen, } 3.0 \mathrm{~T}(\mathrm{PS}) \\
\text { Maastricht, } 3.0 \mathrm{~T}\end{array}$ & 2 & 28 & $4 \mathrm{~mm}$ & 160 & 2000 \\
\hline
\end{tabular}


uncorrected). In order to detect weak activity within and surrounding the lesioned or denervated regions, retinotopic mapping experiments were also analyzed with a lowered correlation threshold of $r>0.2$. The boundaries of retinotopic cortical areas V1, V2, V3, VP, V3A and $\mathrm{V} 4 \mathrm{v}$ were estimated based on the polar angle mapping results.

For anatomical reference, the statistical maps computed were superimposed on the 3D T1-weighted scans. Moreover, following cortex segmentation, inflation, and flattening, the functionally defined early visual areas as well as the lesions (PS) were projected on the patient's and control subjects' 3D representations of the white-gray matter border and/or on cortical flat maps.

\section{Results}

\section{Perimetry}

PS' visual field plots are shown in Fig. 1. They demonstrate full fields for the moving high contrast target (top). A small homonymous paracentral scotoma is seen in the upper left quadrant (highlighted in red). Static perimetry of the central $60^{\circ}$ revealed additional regions of blindness for the right eye (bottom, indicated by black dots). As the patient responded to the stimulus when it was presented at the corresponding retinal positions of the left eye, the defects are of prechiasmatic origin (most likely damages of the right eye's retina due to a small hemorrhage following the accident).

\section{Low-level vision}

\section{Color perception/discrimination}

PS' error score at the Farnsworth-Munsell 100-Hue test was 145. Considering her age, PS' score corresponds to a low normal discrimination ( $95 \%$ error score for $51-55$ years old is 154 ). While PS had a tendency for more errors in the yellow/blue direction than in the red/green direction, the magnitude of errors was not unusual for color normals over age 40 .

\section{Anatomy}

\section{Patient PS}

The precise neuroanatomically based delineation of PS' lesions was undertaken by using different visual representations of the anatomical information obtained: (a) reconstructed T1weighted MR images (Fig. 2), (b) 3D visualizations of the whitegray matter boundary of both hemispheres (Fig. 3), and (c) further processed visualizations in the form of cortical flat maps (Fig. 4).

The major lesion of PS (size: $\sim 8830 \mathrm{~mm}^{3}$ ) is located in the posterior part of the right-sided ventral occipitotemporal cortex (center of gravity in Talairach space: $26,-80,-14$ ), partially damaging the inferior occipital, lingual, and posterior fusiform gyri, but sparing entirely the parahippocampal and the anterior/ mid-fusiform gyri. Another smaller right-hemisphere lesion $\left(\sim 1900 \mathrm{~mm}^{3}\right)$ is situated more anteriorly and laterally within the middle temporal gyrus $(62,-30,-14)$, sparing the right MFG. A third, left-sided lesion $\left(\sim 7084 \mathrm{~mm}^{3}\right)$ encompasses mainly the posterior and mid-fusiform gyrus and parts of the inferior occipital and lingual gyri $(-39,-59,-15)$. Finally, the anatomical images also demonstrated a posterior medial lesion $\left(\sim 3724 \mathrm{~mm}^{3}\right)$ of the left cerebellar hemisphere $(-13,-69,-33)$, which can partially be seen in Fig. 2 (see two bottom boxes). The locations of PS' lesions can most clearly be visualized on $3 \mathrm{D}$ cortex representa- tions of the gray matter boundary (Fig. 3) and cortical flat maps (Fig. 4).

\section{Control subjects}

The high-resolution T1-weighted images of both control subjects showed no structural brain abnormalities (not shown).

\section{Functional results}

\section{Prosopagnosic patient PS}

The delineation of the central and peripheral parts of the right visual field could be defined well within the left hemisphere. In the right hemisphere, the representation of the left peripheral visual field is entirely preserved. However, the cortical representation of the central part of the left upper visual hemifield could not be specified at all because the posterior lesion concerns this area of retinotopic cortex.

The borders of early visual areas in the left hemisphere could be delineated well. However, in accordance with the results of the eccentricity mapping, a precise delineation of the cortical representations within the right hemisphere could not be performed. Yet, sensitivity to the different visual quadrants could be observed (Fig. 5A). The representation of the central part of the left lower visual field is substantially smaller compared to the representation of the right lower visual field within the left hemisphere (Fig. 5B).

Face-preferring activation was replicated in the right 'FFA' (Rossion et al., 2003a; Schiltz et al., 2006), but could also be shown for a left inferior occipital region (possibly 'OFA') and within the right posterior STS. 'PPA', dorsal LOC (dLOC), and hMT+/V5 could be localized bilaterally. The anterior/ventral part of LOC - vLOC - could only be specified within the right hemisphere, and area V4/V8 was observed only in the left occipital cortex (see Fig. 6A).

\section{Control subjects $C G$ and $B S$}

The delineation of the early visual areas succeeded for both control subjects in either hemisphere. Fig. 5C exemplarily demonstrates the normal topography of the retinotopic borders in the right hemisphere of one control subject (BS) and the delineation of the central and peripheral aspect of the left visual field. The functional regions 'FFA', STS, 'OFA', 'PPA', vLOC, dLOC, V4/V8 and $\mathrm{hMT}+\mathrm{V} 5$ could be precisely defined for the control subjects $\mathrm{CG}$ and BS. The ROIs defined for subject BS are presented on anatomical MR slices in Fig. 6B.

Table 3 provides Talairach coordinates, Brodmann areas (BAs), $t$-values, and cluster sizes of all activation sites determined both for PS and the control subjects.

\section{Discussion}

The goals of this paper were to help clarify the critical functional neuroanatomy of face processing in general and to provide extensive information about the structure and function of the visual cortex in a single case of prosopagnosia with a deficit restricted to face recognition (PS; Rossion et al., 2003a; Caldara et al., 2005; Schiltz et al., 2006).

Prosopagnosia is extremely rare, occurring in less than $1 \%$ of brain-damaged patients (Sergent and Villemure, 1989). For example, Zihl and Von Cramon (1986) did not find any pure prosopagnosics in a series of 258 patients suffering from posterior brain lesions of different origins (closed head injury, encephalitis, 

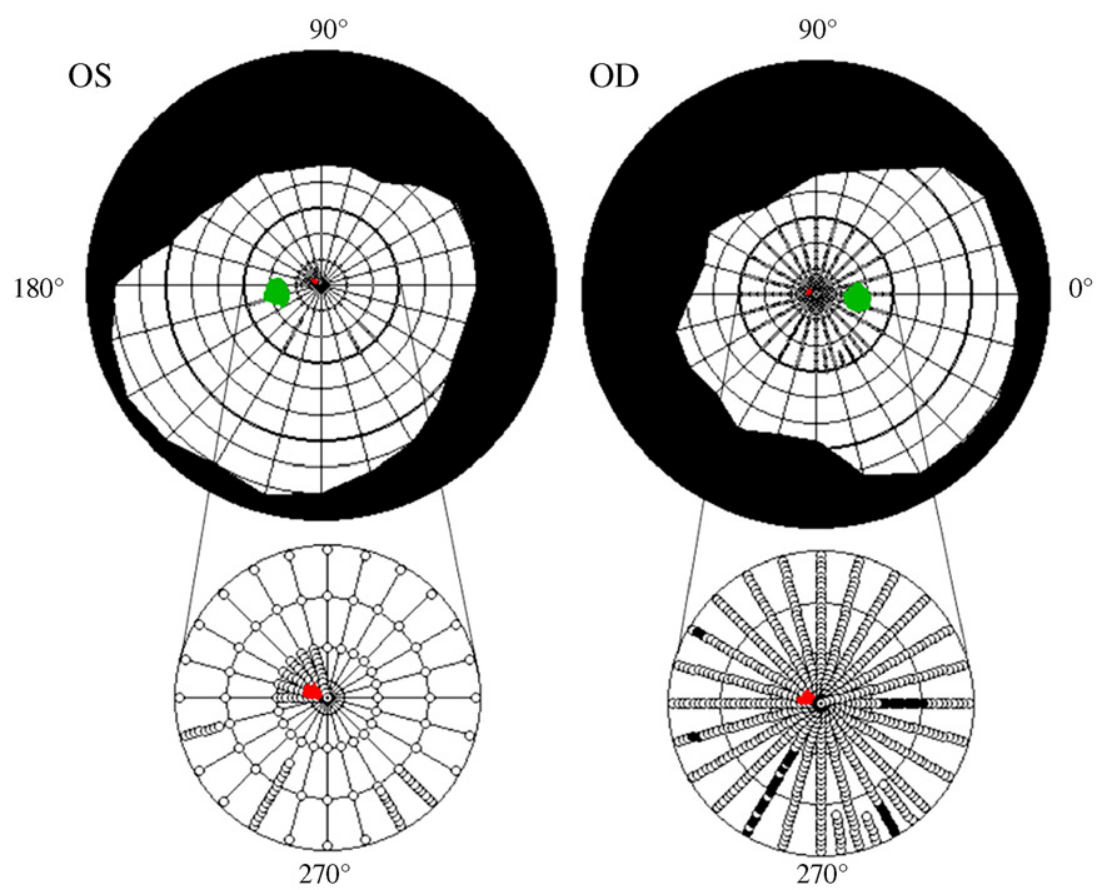

Fig. 1. Results of the perimetry of patient PS. Plots of PS' visual fields for the left (OS) and the right eye (OD) which are based on a combination of static and dynamic perimetry using a white $116^{\circ}, 320 \mathrm{~cd} / \mathrm{m}^{2}$ stimulus on a white $10 \mathrm{~cd} / \mathrm{m}^{2}$ background. Dynamic perimetry was used to map the borders, the blind spots (in green), and the small paracentral homonymous scotoma in the upper left quadrant (in red) that is barely visible in the upper plots. The central regions $\pm 30^{\circ}$ (bottom) were mapped with $200 \mathrm{~ms}$ presentations of the same stimulus. Only heteronymous circumscribed defects were registered in the right eye (indicated by black dots) (remarks: white dots indicate successful light detection, red regions/black dots indicate missed light detection).

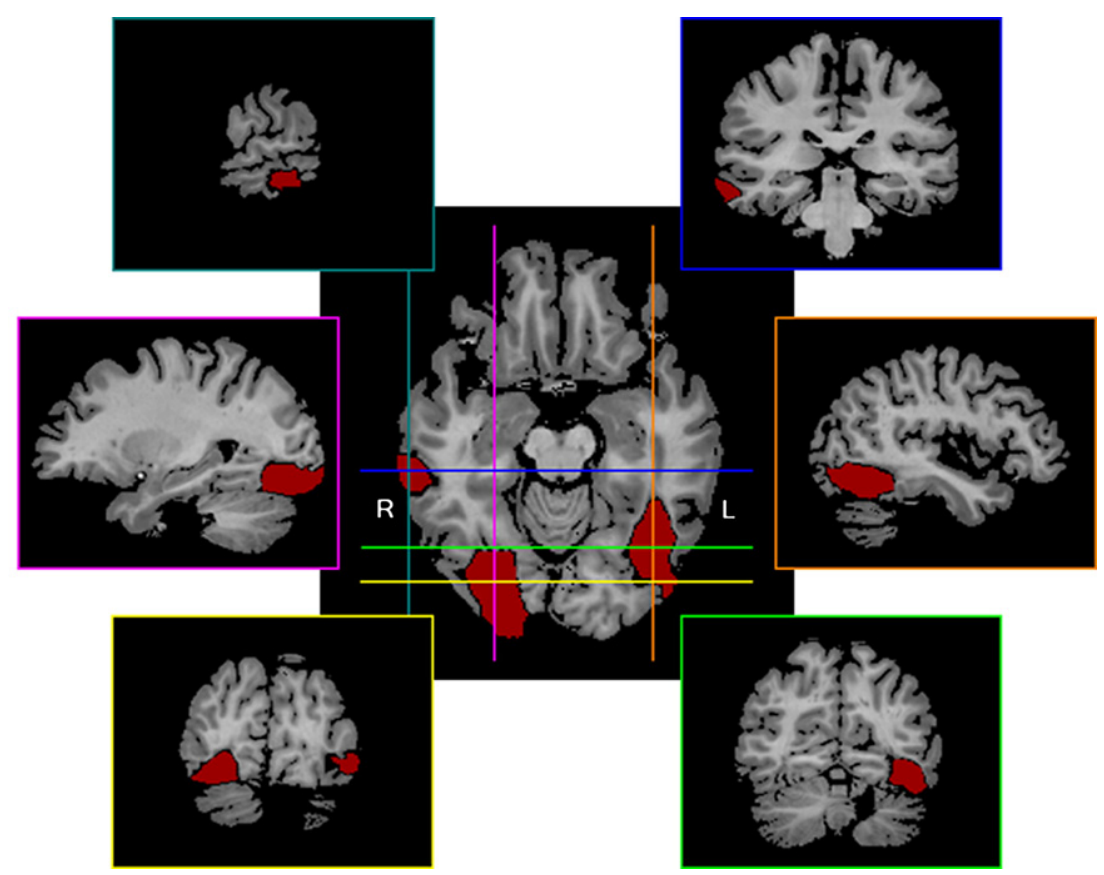

Fig. 2. PS' lesions on reconstructed T1-weighted MR images. The locations of the bilateral but asymmetrical cerebral lesions (indicated in red) are shown on representative anatomical MRI slices (green: $y=-63$, magenta: $x=26$, yellow: $y=-77$, orange: $x=-40$, blue: $y=-31$, turquoise: $x=61$ ). The main lesion is situated in the posterior part of the right ventral occipitotemporal cortex. A smaller lesion is located within the right middle temporal gyrus. A third lesion encompasses the medial part of the left ventral occipitotemporal cortex. Note also the posterior medial lesion of the left cerebellar hemisphere visible in the two bottom boxes (not marked in red) (remarks: R — right hemisphere, L-left hemisphere). 


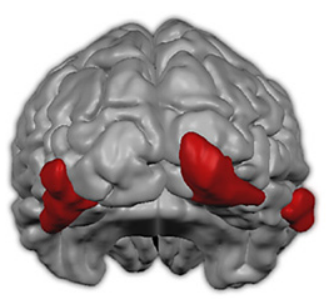

A

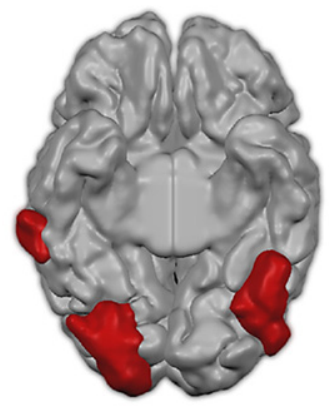

B

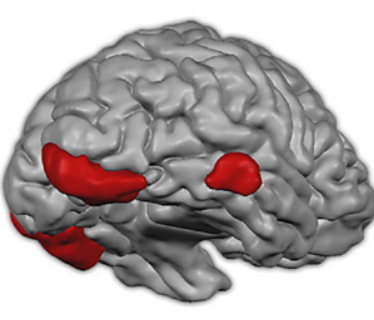

C

Fig. 3. PS' lesions visualized on 3D representations of the gray matter boundary. The figure shows $3 \mathrm{D}$ cortex reconstructions following the segmentation of the gray matter boundary. The lesioned regions are displayed in red so that the $3 \mathrm{D}$ extent of all lesions becomes apparent (remarks: $\mathrm{A}=$ posterior, $\mathrm{B}=\mathrm{ventral}$, $\mathrm{C}=$ ventrolateral view).

tumors, surgical lesions for epilepsy, hemorrhages, and cerebral infarcts). If prosopagnosia is considered as one symptom among other visual and neuropsychological defects, the frequency is higher (for example 6\% in the study of Hécaen and Angerlergues (1962) concerning 382 patients with posterior cerebral lesions of different origins).

Moreover, there are only a few reports with detailed neurological information (e.g., Damasio et al., 1982; Barton et al., 2002) and no articles with defining the lesions leading to face processing impairments with respect to retinotopic areas and high-level visual regions (Michel et al., 1989).

Because a deficit restricted to the category of faces is extremely rare (e.g., De Renzi, 1986; Sergent and Signoret, 1992), a particular interest of the present patient report consists of the fact that PS presents a massive prosopagnosia while having remarkably preserved other visual functions and object recognition abilities (Rossion et al., 2003a; Schiltz et al., 2006). Indeed, whereas acquired prosopagnosic patients are generally found to be impaired at subordinate judgments of non-face categories (e.g., Damasio et al., 1982) - especially when response times are taken into account (Gauthier et al., 1999; Laeng and Caviness, 2001) - PS does not present such difficulties (Schiltz et al., 2006).
Notwithstanding the rarity of prosopagnosia, there is a large amount of variability with regard to the extent and localization of the lesions in prosopagnosic patients (e.g., Meadows, 1974; Damasio et al., 1982; Michel et al., 1989; Sergent and Signoret, 1992; Barton et al., 2002; Bouvier and Engel, 2006). This precludes direct generalizations from the described lesion pattern of the patient PS to other cases. Nonetheless, the detailed anatomical and functional findings may help to answer hitherto unresolved questions concerning the critical brain regions involved in face processing and their interactions.

Our detailed investigation of the brain-damaged prosopagnosic patient PS has allowed us to go several steps further than previous studies in clarifying the neurofunctional anatomy of face (and object) processing. First, the localization of the critical lesion of prosopagnosia in this case and many others (Bouvier and Engel, 2006) is defined here at a sulcal/gyral level on segmented and flattened cortex representations. Second, besides replicating the activation of the right 'FFA' for faces (Rossion et al., 2003a), the meta-analysis of face localizers in the patient disclosed preferential activation for faces in the right STS and in the left 'OFA' for the first time. These observations have several implications for our understanding of the functional relationships between 'face areas' in the healthy human brain. Third, the description of the lesions

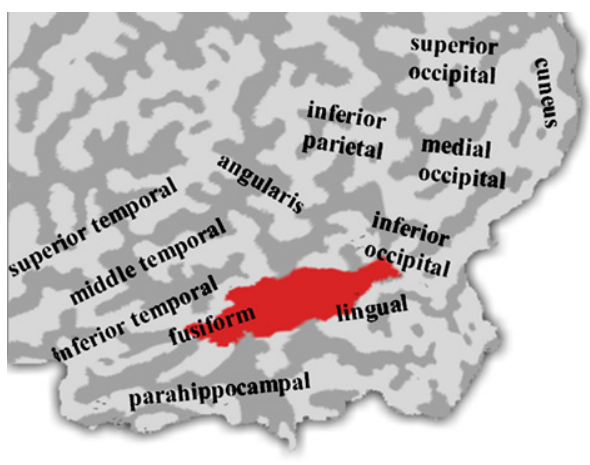

A

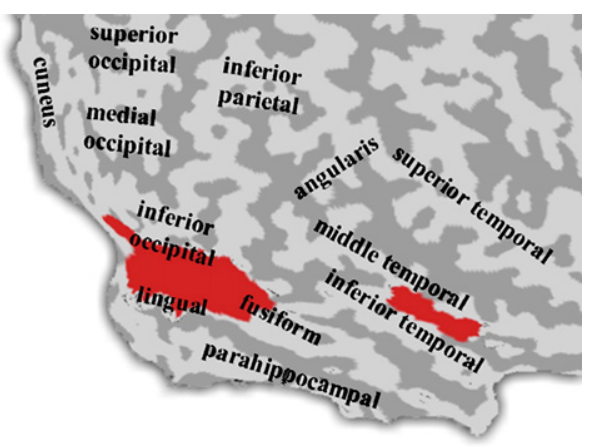

B

Fig. 4. PS' lesions shown on cortical flat maps. The patient's lesions are displayed on cortical flat maps created following cortex inflation, and flattening. Marking the lesions' boundaries in red makes the lesions' locations with respect to well-known human gyri (labeled) and sulci (not labeled) clearer. Furthermore, this visualization demonstrates which anatomical structures are affected by the lesions (remarks: $\mathrm{A}=$ left, $\mathrm{B}=$ right hemisphere; light gray on flat map=convex brain surface folding, dark gray= concave brain surface folding; anatomically based calcarine cut). 
with respect to retinotopic visual areas allows a better understanding of the impaired and preserved visual functions of the patient. Finally, and perhaps most importantly, we localized a normal activation for object shapes, the LOC, in both the dorsal (both hemispheres) and ventral stream (right hemisphere). The ventral LOC in the right hemisphere is located next to the posterior lesion. The observation of an LOC region that is structurally and functionally intact is in line with the preserved object recognition and discrimination abilities of the patient. These findings will be discussed in turn.

\section{The neuroanatomy of prosopagnosia}

\section{The critical role of the right inferior occipital cortex}

Despite the inter-individual variability in terms of extent and localization of the lesions subtending prosopagnosia, it is generally accepted that the critical sites concern the lingual, fusiform and parahippocampal gyri, with right-hemisphere dominance (Meadows, 1974; Michel et al., 1989; Sergent and Signoret, 1992). There is a general consensus that a lesion of the right hemisphere is necessary to cause prosopagnosia, even though one left-handed patient has been reported with a lesion restricted to the left hemisphere (see Mattson et al., 2000). However, the question whether a right-hemisphere lesion alone is sufficient to cause prosopagnosia, or if a bilateral lesion is always necessary, has proven to be more difficult to resolve (Damasio et al., 1982; Michel et al., 1989). This debate originated from the observation of a large proportion of defects in the left superior part of the visual field associated with prosopagnosia, supporting the view that prosopagnosia could follow a unilateral right-hemisphere lesion (see Hécaen and Angerlergues, 1962; Meadows, 1974; and more recently Goldsmith and Liu, 2001; Bouvier and Engel, 2006). PS' condition is a typical example of such an association of deficits. Even though the localization of visual defects could not be taken as decisive evidence for the necessity of a right-hemisphere lesion (Damasio et al., 1982), during the past 20 years, several cases of prosopagnosia have been described with a lesion limited to the right hemisphere (De Renzi, 1986; Landis et al., 1998; 3 cases in Barton et al., 2002; Marotta et al., 2001: case 2; Sergent and Signoret, 1992: cases 1 and 2; Uttner et al., 2002; Wada and Yamamoto, 2001), most of them following right posterior cerebral artery infarct. Sergent and Villemure (1989) also reported the case of a right-hemispherectomized patient suffering from prosopagnosia, whose intellectual and cognitive functions were otherwise almost normal.

It should be noted that in the absence of functional neuroimaging data in such cases one cannot exclude that the posterior righthemisphere lesion causes a functional depression of face responses in the left hemisphere, possibly contributing to the face recognition impairment. Here, such responses could not be found in the left MFG because it was also damaged. Yet, interestingly, we observed for the first time a clear response to faces in the left inferior occipital cortex of the patient, that we labeled "left 'OFA" despite its rather posterior and medial location as compared to control subjects (cf. Table 4). It should also be noted that, given the etiology of the lesion (closed head injury), one cannot exclude that there might also be minor brain damage such as axonal shearing or other (micro-)lesions not detectable with the spatial resolution of the imaging methods used in our study which may contribute to the face processing deficit in PS, in addition to this dominant right inferior occipital damage.

The dominance of right-hemisphere lesions as a generator for prosopagnosia is in line with the established right-hemisphere dominance for face processing in general (e.g., Hillger and Koenig,
1991; Kanwisher et al., 1997; McCarthy et al., 1997; Rossion et al., 2000, 2001; Sergent et al., 1992; Zangenehpour and Chaudhuri, 2005; Le Grand et al., 2003; Schiltz and Rossion, 2006). Most interestingly, a recent meta-analysis shows that the maximal spatial overlap between the lesions of several cases of prosopagnosia with sufficiently documented anatomical report concerns the region located in the right inferior occipital gyrus - posterior to the fusiform gyrus (Bouvier and Engel, 2006), exactly where the main damage is found in PS' brain (Figs. 2-6). This strongly suggests that the damage to the right inferior occipital gyrus was critical in causing PS' prosopagnosic deficit.

Neuroimaging studies of healthy subjects consistently report face-preferring activation in this right inferior occipital region ('OFA', Haxby et al., 2000), as was also found in the control participants of this study (cf. Table 3$)^{3}$. The level and extent of facepreferring activation in this posterior brain region are generally weaker than in the right MFG, the latter being dubbed for this reason by some authors as a 'face module' for face perception ('FFA', Kanwisher et al., 1997; McCarthy et al., 1997). However, both the lesion overlap method (Bouvier and Engel, 2006) and our detailed anatomical data in a pure case of prosopagnosia suggest that the right 'OFA' is a critical region for the recognition of individual faces. Admittedly, a lesion restricted to the right 'FFA' could have comparable or greater effects. However, the critical role of the right 'FFA' in causing prosopagnosia is currently unknown because the prosopagnosic patients that have been reported with right fusiform lesions also appear to have lateral occipital damage in the same hemisphere (e.g., Barton et al., 2002; Wada and Yamamoto, 2001). Moreover, even if the lesion concerned the right 'FFA' only, the patients may not show any activation for faces in the right inferior occipital cortex in the absence of a right 'FFA' (see the discussion in Rossion et al., 2003a; Schiltz et al., 2006).

\section{The contribution of the left MFG/mid-ventrotemporal cortex}

In the left hemisphere, PS' lesion encompasses the fusiform gyrus, where face-preferring responses have also been observed in the healthy human brain (including in this study, see Table 3). The lesion is symmetric to her anatomically preserved right fusiform gyrus ('FFA', see above, Figs. 2-6). So far, no patient with prosopagnosia has been reported in the literature whose lesions are restricted to the left hemisphere, except the left-handed patient already mentioned (Mattson et al., 2000). However, a left-sided defect in addition to right-hemisphere lesions may be important in certain cases (Ettlin et al., 1992). Thus, we cannot completely rule out that the left-sided lesion plays an additional role in the prosopagnosic deficit reported here.

The fact that there exists only a single reported case of prosopagnosia following a lesion restricted to the left hemisphere is remarkable, given that the left hemisphere also contributes to normal face processing, as evidenced by lateralized visual field experiments (e.g., Hillger and Koenig, 1991), and more recently by neuroimaging (e.g., Sergent et al., 1992; Haxby et al., 2000) and event-related potential (e.g., Rossion et al., 2003b) studies. Face processing performed in the left hemisphere may not be critical but

\footnotetext{
${ }^{3}$ In $42(82.4 \%)$ out of 51 subjects investigated recently by our group using a 1.5T scanner (see Rossion et al., 2003a,b, Schiltz et al., 2006; Schiltz and Rossion, 2006), the right 'OFA' could be determined. Among these subjects were two age- and sex-matched controls (concerning PS), both showing right-sided face-preferring activity in 'OFA'.
} 
rather complementary to a massively right localized function in the normal brain. Alternatively, a lesion in the left occipitotemporal cortex may cause only subtle face processing deficits that are usually not detected by conventional neuropsychological tests, perhaps because left unilateral brain-damaged patients present other, more spectacular symptoms (e.g., pure alexia, see Farah, 1990).

Interestingly, the left hemisphere lesion of the patient encompasses (at least partially) the so-called 'visual word form area' ('VWFA') - a portion of the left fusiform gyrus that apparently contains a population of neurons that is tuned to invariant stimulus properties and structural regularities characteristic of written words (Talairach location: $x=-43, y=-54, z=-12$; McCandliss et al., 2003). In general, PS' reading abilities are good, although she reports minor difficulties that may (PS' reading speed is slightly slowed down, see Table 1) or may not (she reports difficulties in correcting orthographic irregularities) be due to her visual field defects. Further studies are currently performed taking advantage of the unique opportunity offered by this single case to learn more about the debated role of the 'VWFA' (see Cohen and Dehaene, 2004; Price and Devlin, 2003).

\section{Minor lesions of PS}

The two remaining smaller regions damaged in PS are unlikely to play a critical role in causing the prosopagnosic impairment.

It seems improbable that the right-sided anterior/lateral lesion located in the middle temporal gyrus plays a critical role in the prosopagnosic deficit because: (1) in most cases of prosopagnosia, this region is not structurally damaged (Bouvier and Engel, 2006) and (2) it does not regularly demonstrate a face-preferring activation in functional neuroimaging studies in healthy subjects (solely Halgren et al. (1999) found weak face-responsive activation in the middle temporal gyrus anterior to hMT+/V5), even though it is admittedly hard to find because of the prevalent EPI distortion within this region. Yet, intracranial recordings in epileptic patients showed an N200 component responsive to faces on the surface of the middle temporal gyrus (Allison et al., 1999). Regions of the right middle temporal gyrus have also been found to be involved in several functions which are not critical for facial identity recognition but are somewhat related to face processing, such as lip-reading (Ludman et al., 2000), visual self-processing (Kicher et al., 2000), and eye-gaze perception (Wicker et al., 1998). The integrity of these functions in the patient PS could be tested in future studies.

Although the posterior medial part of the left cerebellar hemisphere is damaged in PS (see Fig. 2), there are no indications of any deficits in motor behavior or symptoms of a cerebellar cognitive affective syndrome (CCAS, see Schmahmann, 2004). Because there is no empirical evidence for an involvement of the cerebellum in face recognition, it is highly improbable that this lesion plays any role in her face perception impairment.

\section{Higher level visual cortex mapping}

We succeeded in mapping the intact part of the patient's visual system functionally by using the results of the control participants as a reference. We could quite precisely determine the functional regions most likely affected by the lesions (cf. Figs. 5 and 6). To our knowledge, such a detailed investigation has not been performed in previous cases of prosopagnosia. Generally, the Talairach coordinates determined for the control subjects' ROIs corresponded well to the locations reported in previous studies (cf. Table 4). The Talairach coordinates determined for the patient's ROIs corresponded less well. The location of the left 'OFA', for example, is rather posterior and medial, but similar coordinates for this region have been found in healthy subjects (see Rossion et al., 2003a). Moreover, one has to consider a possible shift of brain tissue as a result of the brain damage.

\section{Retinotopic early visual areas}

The early visual areas in the left hemisphere are mostly preserved, but the right-sided retinotopic cortex largely fell victim to the extensive posterior lesion (see Figs. 5A and B). The lesion damaged mostly the cortical representation of the central part of the left upper visual field and thus accounts for her visual defect identified in the perimetry examination (Fig. 1). Scotomas in the left visual field, in particular in the upper part, are common in prosopagnosic cases (Meadows, 1974; Bouvier and Engel, 2006) reflecting the dominance of right-sided ventral cortical lesions causing this deficit. Even though visual field defects are nearly always present, these are not sufficient to account for the prosopagnosic disorder (Meadows, 1974).

\section{Face-preferring visual regions}

Replicating previous observations (Rossion et al., 2003a; Schiltz et al., 2006), a face-preferring region was detected within the right fusiform gyrus ('FFA') of PS. In addition, the left 'OFA' and right posterior STS activation could be shown for the first time in PS, probably because the statistical power was dramatically improved in the present study by combining six functional runs (collected in three MR sessions). The observation of multiple facepreferring regions is in agreement with a distributed view of face processing in the human brain (Haxby et al., 2000; Tovee, 1998). The lack of finding left STS activation is not that surprising given that STS activation during face processing is predominantly found in the right hemisphere (e.g., Chao et al., 1999).

As expected by the location and extent of her major right posterior inferior lesion, no right-sided 'OFA' could be localized in PS' visual cortex, as in our previous recordings. At first glance, this region may simply be more critical for face processing because it is thought to be located at the front-end of the face processing system (Haxby et al., 2000) and its disruption might then disable a whole set of successive face processes, making it impossible to encode rich facial representations in memory in more anterior cortical regions for instance. In accordance with such a hierarchical view with a front-end 'station' in the occipital pole, Haxby et al. (2000) defined the face-preferring region of the inferior occipital gyrus as a gateway to the rest of the face processing system, providing output to face-preferential regions in the ipsilateral fusiform gyrus and posterior STS. However, the neuroimaging data of patient PS do not fit with this view because, despite her posterior lesion, PS presents, a large activation for faces in the right 'FFA' and also in the posterior part of the ipsilateral STS. Similarly, Steeves and colleagues (2006) recently reported another brain-damaged case of prosopagnosia, DF, with bilateral inferior occipital lesions and yet bilateral face-preferring activations in 'FFA' and STS. Together, these observations suggest that, in healthy subjects, anterior facerelated activations in both the fusiform gyrus and STS may also be elicited independently of the contribution of the ipsilateral inferior occipital cortex. While the patient DF, reported by Steeves and collaborators (2006), has bilateral inferior occipital lesions, one cannot fully exclude that PS' face-preferring response in the right fusiform gyrus or STS originates from inputs of the left hemisphere (e.g., from the left 'OFA'). However, this is unlikely because right 
'FFA' activation can be found without activation of the left 'OFA' in healthy subjects and in PS (e.g., Rossion et al., 2003a; Schiltz et al., 2006).
Finally, it might seem surprising that a large number of facepreferring regions (right STS and 'FFA', left 'OFA') are strongly active in the brain of a patient who is largely unable to recognize

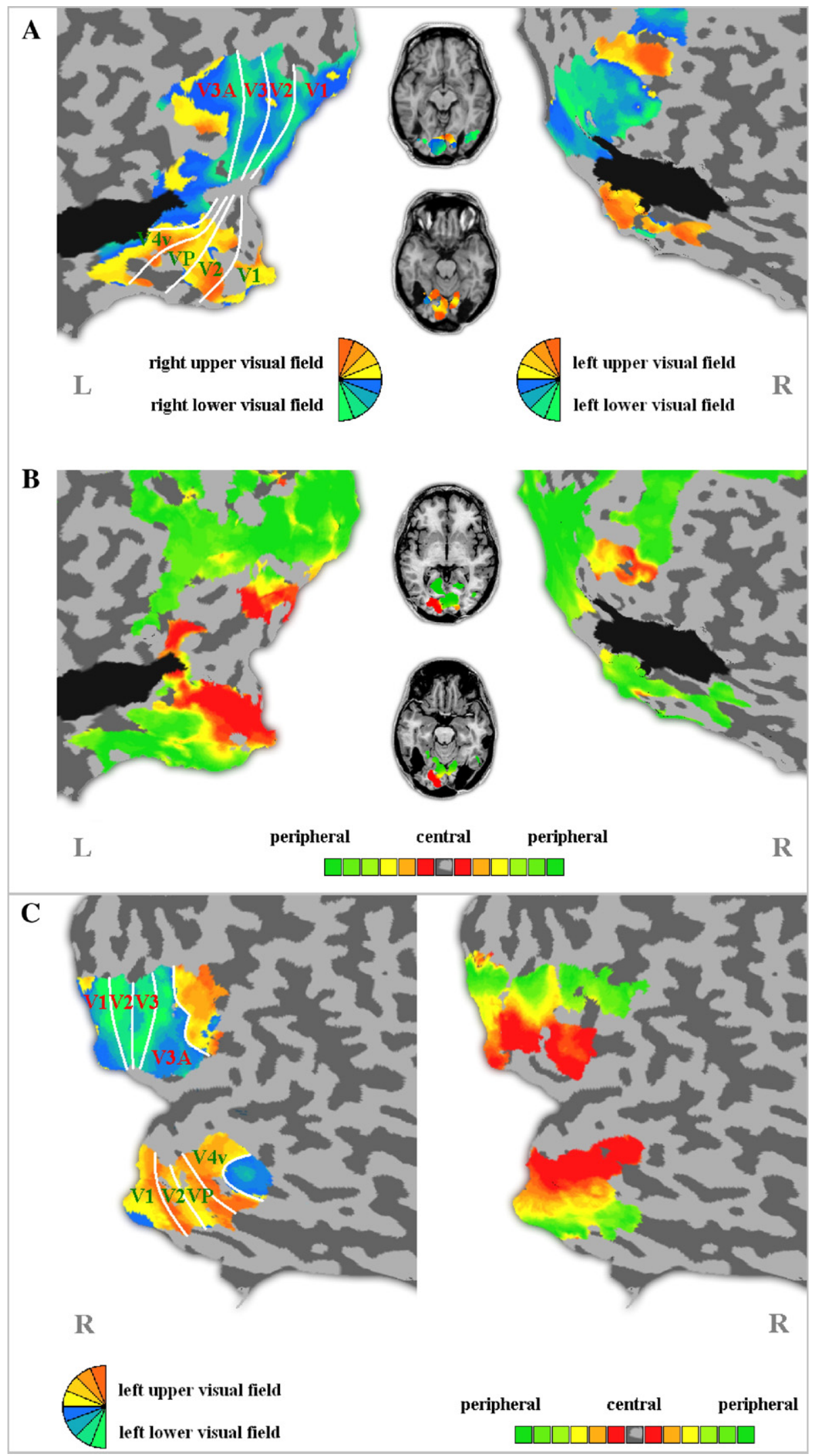




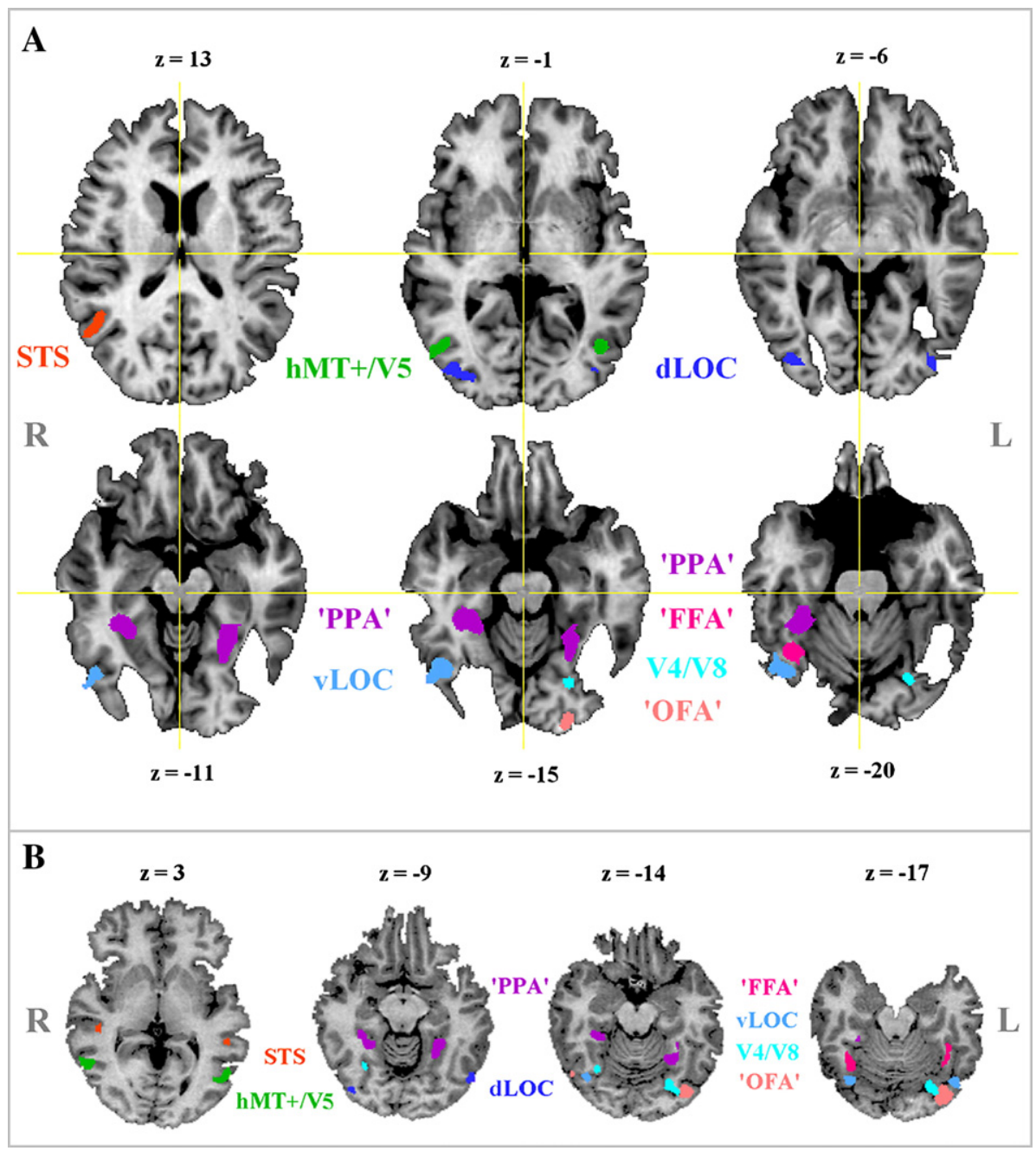

Fig. 6. Functional regions of interest of the patient PS (A) and the control subject BS (B). Functionally defined visual regions of the patient PS (A) and the control subject BS (B) are superimposed on T1-weighted anatomical MRI slices (remarks: R=right hemisphere, $\mathrm{L}=$ left hemisphere).

faces. However, these regions, albeit presenting a preferential response to faces, might not process faces adequately. In agreement with this view, more recent neuroimaging data of patient PS indicate that the right 'FFA' activation, albeit being normal at a quantitative level, is qualitatively different compared to control subjects: whereas healthy subjects show a decreased BOLD response when being presented with blocks or pairs of identical faces compared to different faces, PS' 'FFA' shows the same level of activation for same and different faces (Schiltz et al., 2006). This suggests that the right 'FFA' (possibly also the STS) is not functionally intact, perhaps missing reentrant connections of the damaged ipsilateral 'OFA' (see discussion in Rossion et al., 2003a; Schiltz et al., 2006; Steeves et al., 2006). It should be stressed here that looking at a face initiates a multitude of different processes, besides identity processing. Although slowed down, PS is still able to detect faces and categorize them according to their gender, age, and expression (Rossion et al., 2003a). Her ability to discriminate individual faces is also clearly impaired, but is much better than chance level, especially if she is given unlimited time (Rossion et al., 2003a; Schiltz et al., 2006). Thus, the different regions showing a preferential response for faces may still play a role in her preserved face perception abilities (see also Marotta et al., 2001). Alternatively, PS may rely on other intact higher visual regions which do not process faces preferentially, such as the vLOC (see below).

Following the detailed mapping of the visual cortex of the patient, these questions will be addressed in future experiments, combining functional neuroimaging and psychophysical investigations to correlate brain activity patterns and behavioral outcome.

Fig. 5. Results of the retinotopic mapping experiments of the patient PS (A and B) and of the control subject BS (C). (A) Retinotopic polar maps of both hemispheres of the patient PS are superimposed on cortical flat maps and anatomical slices in neurological convention (upper slice: $z=-8$, lower slice: $z=-17$ ). The early visual areas could be delineated in the left hemisphere only. (B) Retinotopic eccentricity maps of both hemispheres of the patient PS are superimposed on cortical flat maps and anatomical slices in neurological convention (upper slice: $z=-2$, lower slice: $z=-15$ ). (C) Retinotopic polar (left) and eccentricity (right) maps of the right hemisphere of the control subject BS and the resultant classification of the early visual areas superimposed on cortical flat maps (remarks: $\mathrm{R}=$ right hemisphere, $\mathrm{L}=$ left hemisphere; lesions are displayed in black; functionally/retinotopically based calcarine cut; light gray on flat map $=$ convex brain surface folding, dark gray $=$ concave brain surface folding). 
Table 3

Talairach locations, $t$-values and cluster sizes of the functionally defined key regions

\begin{tabular}{|c|c|c|c|c|c|c|c|c|c|c|c|c|c|}
\hline \multirow{3}{*}{ Subject } & \multirow[t]{3}{*}{ Region } & \multicolumn{6}{|c|}{ Left hemisphere } & \multicolumn{6}{|c|}{ Right hemisphere } \\
\hline & & \multicolumn{3}{|c|}{ Talairach coordinates } & \multirow[t]{2}{*}{$t$} & \multirow[t]{2}{*}{$\mathrm{BA}(\mathrm{s})$} & \multirow{2}{*}{$\begin{array}{l}\text { Cluster size } \\
\text { by } p<.05 \\
\text { (in mm3) }\end{array}$} & \multicolumn{3}{|c|}{ Talairach coordinates } & \multirow[t]{2}{*}{$t$} & \multirow[t]{2}{*}{$\mathrm{BA}(\mathrm{s})$} & \multirow{2}{*}{$\begin{array}{l}\text { Cluster size } \\
\text { by } p<.05 \\
\text { (in } \mathrm{mm} 3 \text { ) }\end{array}$} \\
\hline & & $x$ & $y$ & $z$ & & & & $x$ & $y$ & $z$ & & & \\
\hline \multirow[t]{8}{*}{ PS } & 'FFA' & $\times$ & $\times$ & $\times$ & $\times$ & 37 & $\times$ & 36 & -54 & -20 & 9.0 & 37 & 648 \\
\hline & STS & - & - & - & - & - & - & 45 & -54 & 12 & 7.4 & 22 & 324 \\
\hline & 'OFA' & -22 & -91 & -15 & 7.4 & 18 & 243 & $\times$ & $\times$ & $\times$ & $\times$ & $18 / 19$ & $\times$ \\
\hline & 'PPA' & -26 & -45 & -13 & 10.8 & 37 & $>2000$ & 31 & -38 & -16 & 11.7 & $20 / 37$ & $>2000$ \\
\hline & dLOC & -39 & -82 & -5 & 7.3 & $18 / 19$ & 81 & 38 & -78 & -1 & 7.6 & $18 / 19$ & 351 \\
\hline & vLOC & $\times$ & $\times$ & $\times$ & $\times$ & $19 / 37$ & $\times$ & 44 & -64 & -16 & 8.9 & $19 / 37$ & 891 \\
\hline & hMT+/V5 & -42 & -67 & 1 & 5.25 & $19 / 39$ & 27 & 45 & -67 & 4 & 4.6 & $19 / 37$ & $(27)^{*}$ \\
\hline & V4/V8 & -23 & -70 & -15 & 7.0 & 19 & 135 & $\times$ & $\times$ & $\times$ & $\times$ & & $\times$ \\
\hline \multirow[t]{8}{*}{$\mathrm{CG}$} & 'FFA' & -39 & -50 & -18 & 21.0 & 37 & 1490 & 41 & -53 & -14 & 24.1 & 37 & $>1762$ \\
\hline & STS & -53 & -40 & 14 & 8.9 & $21 / 22$ & 104 & 46 & -40 & 14 & 12.3 & $21 / 22$ & $>716$ \\
\hline & 'OFA' & -38 & -68 & -12 & 8.9 & $18 / 19$ & 148 & 34 & -80 & -6 & 18.2 & $18 / 19$ & $>282$ \\
\hline & 'PPA' & -29 & -39 & -8 & 8.4 & $20 / 37$ & 810 & 27 & -38 & -10 & 6.6 & $20 / 37$ & 405 \\
\hline & dLOC & -42 & -69 & -4 & 6.0 & 19 & 81 & 40 & -67 & -6 & 7.0 & 19 & 1197 \\
\hline & vLOC & -42 & -68 & -18 & 5.0 & $19 / 37$ & 54 & 40 & -64 & -19 & 8.6 & $19 / 37$ & 444 \\
\hline & hMT+/V5 & -48 & -63 & -2 & 10.4 & $19 / 37$ & 1053 & 42 & -62 & -4 & 12.8 & $19 / 37$ & $>2000$ \\
\hline & V4/V8 & -35 & -70 & -8 & 10.9 & $19 / 37$ & 225 & 30 & -61 & -11 & 5.3 & $19 / 37$ & 27 \\
\hline \multirow[t]{8}{*}{ BS } & 'FFA' & -36 & -44 & -18 & 8.5 & 37 & 223 & 37 & -50 & -22 & 21.9 & 37 & 1548 \\
\hline & STS & -50 & -38 & 6 & 8.4 & $21 / 22$ & 172 & 44 & -28 & 3 & 7.9 & $21 / 22$ & 213 \\
\hline & 'OFA' & -34 & -76 & -16 & 15.3 & $18 / 19$ & 903 & 48 & -62 & -14 & 6.4 & $18 / 19$ & 104 \\
\hline & 'PPA' & -2 & -50 & -11 & 12.0 & 37 & $>2000$ & 26 & -43 & -12 & 11.6 & 37 & $>2000$ \\
\hline & dLOC & -47 & -68 & -8 & 11.6 & $19 / 37$ & 642 & 38 & -77 & -8 & 10.6 & $18 / 19$ & 567 \\
\hline & vLOC & -40 & -68 & -16 & 12.4 & $19 / 37$ & 540 & 36 & -65 & -15 & 12.4 & $19 / 37$ & 729 \\
\hline & hMT+/V5 & -49 & -63 & 0 & 10.9 & 37 & 1026 & 52 & -54 & 2 & 9.7 & 37 & 594 \\
\hline & V4/V8 & -25 & -72 & -18 & 9.7 & 19 & 840 & 29 & -59 & -11 & 8.5 & $19 / 37$ & 231 \\
\hline
\end{tabular}

$p<0.05$ (1-sided, Bonferroni-corrected), voxel size: $1 \mathrm{~mm}^{3}, \times$ region lesioned. ${ }^{*} p<0.00002$, — region could not be detected, BA $=$ Brodmann area, colored numbers of BAs indicate an affection by lesioning. (For interpretation of the references to colour in this table legend, the reader is referred to the web version of this article.)

Non-face-preferring higher visual brain regions

The bilateral 'PPA' (Epstein et al., 1999), dLOC, and hMT+/V5 (Sunaert et al., 1999) could be localized bilaterally and are entirely spared by the lesions. Previous studies have shown that localized damage to the region of the 'PPA' is associated with topographical agnosia and impairment in scene recognition (Epstein et al., 2001). Although PS has not been tested on scene categorization or recognition, or topographical orientation, she never complained of any corresponding difficulties. Self-reports and observations in everyday life rather suggest that her abilities might be above average. She perfectly recognizes places previously visited and never depends on other people to find her way home, her work place, friends' places, the hospital, a hotel, etc. Given the sparing of the neural substrates of topographical orientation as identified in the present study, it can be predicted that she will perform normally in corresponding tests. The total preservation of her occipitoparietal

Table 4

Talairach coordinates of the functional key regions' determined in previous studies

\begin{tabular}{|c|c|c|c|c|c|c|c|}
\hline \multirow[t]{3}{*}{ Region/area } & \multicolumn{6}{|c|}{ Talairach coordinates } & \multirow[t]{3}{*}{ Reference study } \\
\hline & \multicolumn{3}{|l|}{ Left } & \multicolumn{3}{|c|}{ Right } & \\
\hline & $x$ & $y$ & $z$ & $x$ & $y$ & $z$ & \\
\hline 'FFA' & -38 & -51 & -15 & 39 & -50 & -19 & Chao et al., 1999 \\
\hline STS & -47.5 & -51.5 & 3 & 48 & 52 & 5 & Puce et al., 1998 \\
\hline 'OFA' & -34 & -81 & -14 & 38 & -80 & -7 & Rossion et al., 2003a \\
\hline 'PPA' & -28 & -39 & -6 & 20 & -39 & -5 & Epstein et al., 1999 \\
\hline ALOC & -41 & -75 & 4 & 37 & -71 & 4 & Grill-Spector et al., 1998* \\
\hline vLOC & -39 & -68 & -13 & 41 & -67 & -14 & Grill-Spector et al., 1998* \\
\hline hMT+/V5 & -42 & -66 & 2 & 42 & -62 & 6 & Sunaert et al., 1999 \\
\hline V4/V8 & -26 & -67 & -9 & 26 & -67 & -9 & Tootell \& Hadjikhani, 2001 \\
\hline
\end{tabular}

*These authors differentiate the two subdivisions of LOC as follows: (a) a caudal dorsal lateral occipital part (LO, here dLOC) and (b) a posterior fusiform part (LOa/pFs, here vLOC) (see e.g., Grill-Spector et al., 2001). 
visual system (the 'dorsal stream'), and in particular hMT+/V5 and the dorsal part of the lateral occipital complex (dLOC) (Fig. $6 \mathrm{~A}$ ), is also in agreement with her preserved movement vision and her normal ability to reach and grasp objects. As for the occipitotemporal visual system (the 'ventral stream'), we could define V4/ V8 (Tootell and Hadjikhani, 2001) within the left hemisphere only. PS' color perception ability may only be mildly impaired for central vision (Table 1), and complementary tests performed here clearly confirm that she is not achromatopsic. However, because of the lack of defining right V4/V8, PS may be worse at processing color stimuli in her left visual field. Similarly, damage of the left vLOC does not seem to have a major effect on her nonface object recognition abilities, but this has to be tested with lateralized presentations. Even though PS may possibly have more difficulties recognizing object shapes flashed in her right visual field, the presence of the left scotoma and possibly low-level visual difficulties in the left visual field may balance any hemispheric difference out.

Most interestingly, the right occipital inferior lesion that is thought to be critical in causing PS' prosopagnosia spared entirely the right vLOC (Fig. 6A), a region which is directly correlated with object perception (e.g., Grill-Spector et al., 1998, 2000; Avidan et al., 2002; James et al., 2000). The role of the LOC in the discrimination of individual objects is also supported by fMRI adaptation (Grill-Spector et al., 2006, 2001) or repetition-suppression (Henson and Rugg, 2003) studies, showing a larger response in this region to novel objects than to repeated objects (Avidan et al., 2002; Grill-Spector et al., 1999; Sayres and Grill-Spector, 2006). Accordingly, the sparing of the vLOC demonstrated here may account for PS' preserved object recognition and discrimination abilities (Rossion et al., 2003a; Schiltz et al., 2006). In contrast to PS, the patient DF, first reported by Milner et al. (1991), is massively impaired at object recognition following lesions of the main part of the vLOC in both hemispheres (James et al., 2003). Thus, while the patient DF presents a bilateral lesion including both the vLOC and the 'OFA' and is impaired at both object and face recognition, the patient PS' lesion damaged the right 'OFA' but spared the right vLOC, resulting in a deficit restricted to the category of faces. Taken together, these observations suggest that prosopagnosia is most often associated with object recognition deficits (visual agnosia) because of right inferior occipital and occipitotemporal lesions damaging both the vLOC and the 'OFA'. However, a lesion restricted to the right 'OFA', sparing the right vLOC, may lead to an isolated deficit at face recognition, as observed for the patient PS. This observation of a normal vLOC activation in PS' brain, next to the posterior right hemisphere lesion, also underscores the important role that fMRI (compared to conventional structural MRI) can play in revealing the functional integrity of brain regions that might be potentially damaged (James et al., 2003; Rossion et al., 2003a; Schiltz et al., 2006; Steeves et al., 2006).

\section{Conclusions}

We presented for the first time a detailed study on the functional neuroanatomy of the visual system in a prosopagnosic patient. Our data reinforce the critical involvement of the right inferior occipital gyrus ('OFA') in causing prosopagnosia (Bouvier and Engel, 2006), while supporting the view that a lesion of this region does not interrupt the preferential processing of faces in ipsilateral higher level visual regions such as the 'FFA' (Rossion et al., 2003a; Schiltz et al., 2006) and the STS. Besides the precise definition of the lesions in this single case, the observation of a number of functionally intact visual regions, such as the vLOC, corresponds well with the remarkably well preserved visual functions of the patient - including object recognition - and opens the way for further clarification of the neural basis of her face and object processing abilities. Detailed neurofunctional reports of single cases as reported here should be particularly important to clarify further the neural basis of prosopagnosia and to provide invaluable information about the functional neuroanatomy of face processing in the healthy human brain.

\section{Acknowledgments}

We are extremely grateful to PS for her patience and high motivation during the experiments performed in connection with this study. We thank Petra Stoerig for performing the perimetry examination of PS and providing Fig. 1. Furthermore, we would like to thank Nikolaus Kriegeskorte for his help in fMRI data acquisition, Steve Shevell for his help in interpreting PS' score at the color Farnsworth-Munsell 100-Hue test, Xavier Golay for optimizing the acquisition of anatomical images, as well as Judith Peters, Joel Reithler, and two anonymous reviewers for their enriching comments on a previous version of this paper.

This research was supported by Maastricht University and a grant ARC 01/06-267, (Communauté Française de Belgique-Actions de Recherche Concertées). Bruno Rossion is supported by the Belgian National Foundation for Scientific Research (FNRS).

\section{References}

Allison, T., Puce, A., Spencer, D.D., McCarthy, G., 1999. Electrophysiological studies of human face perception. I: Potentials generated in occipitotemporal cortex by face and non-face stimuli. Cereb. Cortex 9 , 415-430.

Avidan, G., Harel, M., Hendler, T., Ben-Bashat, D., Zohary, E., Malach, R., 2002. Contrast sensitivity in human visual areas and its relationship to object recognition. J. Neurophysiol. 87, 3102-3116.

Barton, J.J., Cherkasova, M.V., 2005. Impaired spatial coding within objects but not between objects in prosopagnosia. Neurology 65, 270-274.

Barton, J.J.S., Press, D.Z., Keenan, J.P., O’Connor, M., 2002. Lesions of the fusiform face area impair perception of facial configuration in prosopagnosia. Neurology 58, 71-78.

Barton, J.J., Cherkasova, M.V., Press, D.Z., Intriligator, J.M., O'Connor, M., 2004. Perceptual functions in prosopagnosia. Perception 33, 939-956.

Benton, A.L., 1980. The neuropsychology of facial recognition. Am. Psychol. 35, 176-186.

Benton, A.L., van Allen, M., 1972. Prosopagnosia and facial discrimination. J. Neurol. Sci. 15, 167-172.

Bodamer, J., 1947. Die Prosop-agnosie. Arch. Psychiatr. Nervenkr. 179, $6-54$.

Boutsen, L., Humphreys, G.W., 2002. Face context interferes with local part processing in a prosopagnosic patient. Neuropsychologia 40, 2305-2313.

Bouvier, S.E., Engel, S.A., 2006. Behavioral deficits and cortical damage loci in cerebral achromatopsia. Cereb. Cortex 16, 183-191.

Boynton, G.M., Engel, S.A., Glover, G.H., Heeger, D.J., 1996. Linear systems analysis of functional magnetic resonance imaging in human V1. J. Neurosci. 16, 4207-4221.

Brodtmann, A., Puce, A., Syngeniotis, A., Darby, D., Donnan, G., 2003. The functional magnetic resonance imaging hemodynamic response to faces remains stable until the ninth decade. NeuroImage 20, 520-528. 
Bruce, V., Young, A., 1986. Understanding face recognition. Br. J. Psychol. 77, 305-327.

Bruyer, R., Laterre, C., Seron, X., Feyereisen, P., Strypstein, E., Pierrard, E., Rectem, D., 1983. A case of prosopagnosia with some preserved covert remembrance of familiar faces. Brain Cogn. 2, 257-284.

Bukach, C.M., Bub, D.N., Gauthier, I., Tarr, M.J., 2006. Perceptual expertise effects are not all or none: spatially limited perceptual expertise for faces in a case of prosopagnosia. J. Cogn. Neurosci. 18, 48-63.

Caldara, R., Schyns, P., Mayer, E., Smith, M., Gosselin, F., Rossion, B., 2005. Does prosopagnosia take the eyes out from faces? Evidence for a defect in the use of diagnostic facial information in a brain-damaged patient. J. Cogn. Neurosci. 17, 1652-1666.

Campbell, R., Landis, T., Regard, M., 1986. Face recognition and lipreading. A neurological dissociation. Brain 109, 509-521.

Castelo-Branco, M., Formisano, E., Backes, W., Zanella, F., Neuenschwander, S., Singer, W., Goebel, R., 2002. Activity patterns in human motionsensitive areas depend on the interpretation of global motion. Proc. Natl. Acad. Sci. U. S. A. 99, 13914-13919.

Chao, L.L., Martin, A., Haxby, J.V., 1999. Are face-responsive regions selective only for faces? NeuroReport 10, 2945-2950.

Clarke, S., Lindemann, A., Maeder, P., Borruat, F.X., Assal, G., 1997. Face recognition and postero-inferior hemispheric lesions. Neuropsychologia $35,1555-1563$.

Cohen, L., Dehaene, S., 2004. Specialization within the ventral stream: the case for the visual word form area. NeuroImage 22, 466-476.

Culham, J.C., Kanwisher, N.G., 2001. Neuroimaging of cognitive functions in human parietal cortex. Curr. Opin. Neurobiol. 11, 157-163.

Damasio, A., Yamada, T., Damasio, H., Corbett, J., McKee, K., 1980. Central achromatopsia: behavioral, anatomic, and physiologic aspects. Neurology 30, 1064-1071.

Damasio, A.R., Damasio, H., Van Hoesen, G.W., 1982. Prosopagnosia: anatomic basis and behavioral mechanisms. Neurology 32, 331-341.

De Renzi, E., 1986. Prosopagnosia in two patients with CT scan evidence of damage confined to the right hemisphere. Neuropsychologia 24, $385-389$.

Dixon, M.J., Bub, D.N., Arguin, M., 1998. Semantic and visual determinants of face recognition in a prosopagnosic patient. J. Cogn. Neurosci. 10, 362-376.

Ellis, H.D., Florence, M., 1990. Bodamer's (1947) paper on prosopagnosia. Cogn. Neuropsychol. 7, 81-105.

Engel, S.A., Rumelhart, D.E., Wandell, B.A., Lee, A.T., Glover, G.H., Chichilnisky, E.J., Shadlen, M.N., 1994. fMRI of human visual cortex. Nature 369, 525.

Epstein, R., Kanwisher, N., 1998. A cortical representation of the local visual environment. Nature 392, 598-601.

Epstein, R., Harris, A., Stanley, D., Kanwisher, N., 1999. The parahippocampal place area: recognition, navigation, or encoding? Neuron 23, $115-125$.

Epstein, R., DeYoe, E.A., Press, D.Z., Rosen, A.C., Kanwisher, N., 2001. Neuropsychological evidence for a topographical learning mechanism in parahippocampal cortex. Cogn. Neuropsychol. 18, 481-508.

Ettlin, T.M., Beckson, M., Benson, D.F., Langfitt, J.T., Amos, E.C., Pineda, G.S., 1992. Prosopagnosia: a bihemispheric disorder. Cortex 28, 129-134.

Farah, M.J., 1990. Visual Agnosia: Disorders of Object Recognition and What They Tell us About Normal Vision. MIT Press, Cambridge.

Farah, M.J., Levinson, K.L., Klein, K.L., 1995. Face perception and withincategory discrimination in prosopagnosia. Neuropsychologia 33, 661-674.

Farnsworth, D., 1957. The Farnsworth-Munsell 100-Hue test for the examination of color vision. Munsell Color Company, Baltimore, MD.

Felleman, D.J., Van Essen, D.C., 1991. Distributed hierarchical processing in the primate cerebral cortex. Cereb. Cortex 1, 1-47.

Gauthier, I., Behrmann, M., Tarr, M.J., 1999. Can face recognition really be dissociated from object recognition? J. Cogn. Neurosci. 11, 349-370.

Gauthier, I., Tarr, M.J., Moylan, J., Skudlarski, P., Gore, J.C., Anderson,
A.W., 2000. The fusiform "face area" is part of a network that processes faces at the individual level. J. Cogn. Neurosci. 12, 495-504.

Goebel, R., Muckli, L., Kim, D.-S., 2003. The visual system. In: Paxinos, G., Mai, J.K. (Eds.), The Human Nervous System. Elsevier Academic Press, San Diego, pp. 1280-1305.

Goldsmith, Z.G., Liu, G.T., 2001. Facial recognition and prosopagnosia: past and present concepts. Neuro-Ophthalmology 25, 177-192.

Grill-Spector, K., Kushnir, T., Edelman, S., Itzchak, Y., Malach, R., 1998. Cue-invariant activation in object-related areas of the human occipital lobe. Neuron 21, 191-202.

Grill-Spector, K., Kushnir, T., Edelman, S., Avidan, G., Itzchak, Y., Malach, R., 1999. Differential processing of objects under various viewing conditions in the human lateral occipital complex. Neuron 24, 187-203.

Grill-Spector, K., Kushnir, T., Hendler, T., Malach, R., 2000. The dynamics of object-selective activation correlate with recognition performance in humans. Nat. Neurosci. 3, 837-843.

Grill-Spector, K., Kourtzi, Z., Kanwisher, N., 2001. The lateral occipital complex and its role in object recognition. Vision Res. 41, $1409-1422$.

Grill-Spector, K., Henson, R., Martin, A., 2006. Repetition and the brain: neural models of stimulus-specific effects. Trends Cogn. Sci. $10,14-23$

Hadjikhani, N., Liu, A.K., Dale, A.M., Cavanagh, P., Tootell, R.B.H., 1998. Retinotopy and color sensitivity in human visual cortical area V8. Nat. Neurosci. 1, 235-241.

Halgren, E., Dale, A.M., Sereno, M.I., Tootell, R.B., Marinkovic, K., Rosen, B.R., 1999. Location of human face-selective cortex with respect to retinotopic areas. Hum. Brain Mapp. 7, 29-37.

Haxby, J.V., Hoffman, E.A., Gobbini, M.I., 2000. The distributed human neural system for face perception. Trends Cogn. Sci. 4, 223-233.

Hécaen, H., Angerlergues, R., 1962. Agnosia for faces (prosopagnosia). Arch. Neurol. 7, 92-100.

Henke, K., Schweinberger, S.R., Grigo, A., Klos, T., Sommer, W., 1998 Specificity of face recognition: recognition of exemplars of non-face objects in prosopagnosia. Cortex 34, 289-296.

Henson, R.N., Rugg, M.D., 2003. Neural response suppression, haemodynamic repetition effects, and behavioral priming. Neuropsychologia 41 , 263-270.

Heywood, C.A., Nicholas, J.J., Cowey, A., 1996. Behavioural and electrophysiological chromatic and achromatic contrast sensitivity in an achromatopsic patient. J. Neurol. Neurosurg. Psychiatry 60, $638-643$

Hillger, L.A., Koenig, O., 1991. Separable mechanisms in face processing: evidence from hemispheric specialization. J. Cogn. Neurosci. 3, 42-58.

James, T.W., Humphrey, G.K., Gati, J.S., Menon, R.S., Goodale, M.A., 2000. The effects of visual object priming on brain activation before and after recognition. Curr. Biol. 10, 1017-1024.

James, T.W., Culham, J., Humphrey, G.K., Milner, A.D., Goodale, M.A., 2003. Ventral occipital lesions impair object recognition but not objectdirected grasping: an fMRI study. Brain 126, 2643-2675.

Joubert, S., Felician, O., Barbeau, E., Sontheimer, A., Barton, J.J., Ceccaldi, M., Poncet, M., 2003. Impaired configurational processing in a case of progressive prosopagnosia associated with predominant right temporal lobe atrophy. Brain 126, 2537-2550.

Kanwisher, N., McDermott, J., Chun, M.M., 1997. The fusiform face area: a module in human extrastriate cortex specialized for face perception. J. Neurosci. 17, 4302-4311.

Kicher, T.T.J., Senior, C., Phillips, M.L., Benson, P.J., Bullmore, E.T., Brammer, M., Simmons, A., Williams, S.C., Bartels, M., David, A.S., 2000. Towards a functional neuroanatomy of self processing: effects of faces and words. Cogn. Brain Res. 10, 133-144.

Kinnear, P.R., Sahraie, A., 2002. New Farnsworth-Munsell 100 hue test norms of normal observers for each year of age 5-22 and for age decades 30-70. Br. J. Ophthalmol. 86 (12), 1408-1411.

Laeng, B., Caviness, V.S., 2001. Prosopagnosia as a deficit in encoding curved surface. J. Cogn. Neurosci. 13, 556-576.

Landis, T., Regard, M., Bliestle, A., Kleihues, P., 1998. Prosopagnosia and 
agnosia for noncanonical views. An autopsied case. Brain 111, $1287-1297$

Le Grand, R., Mondloch, C.J., Maurer, D., Brent, H.P., 2003. Expert face processing requires visual input to the right hemisphere during infancy. Nat. Neurosci. 6, 1108-1112.

Levine, D.N., Calvanio, R., 1989. Prosopagnosia: a defect in visual configural processing. Brain Cogn. 10, 149-170.

Lhermitte, F., Chain, F., Escourolle, R., Ducarne, B., Pillon, B., 1972. Anatomoclinical study of a case of prosopagnosia. Rev. Neurol. 126, 329-346.

Linden, D.E.J., Kallenbach, U., Heinecke, A., Singer, W., Goebel, R., 1999. The myth of upright vision. A psychophysical and functional imaging study of adaptation to inverting spectacles. Perception 28, $469-481$.

Ludman, C.N., Summerfield, A.Q., Hall, D., Elliott, M., Foster, J., Hykin, J.L., Bowtell, R., Morris, P.G., 2000. Lip-reading ability and patterns of cortical activation studied using fMRI. J. Audiol. 34, 225-230.

Malach, R., Reppas, J.B., Benson, R.R., Kwong, K.K., Jiang, H., Kennedy, W.A., Ledden, P.J., Brady, T.J., Rosen, B.R., Tootell, R.B., 1995. Object-related activity revealed by functional magnetic resonance imaging in human occipital cortex. Proc. Natl. Acad. Sci. U. S. A. 92, $8135-8139$.

Mattson, A.J., Levin, H.S., Grafman, J., 2000. A case of prosopagnosia following moderate closed head injury with left hemisphere focal lesion. Cortex 36, 125-137.

Marotta, J.J., Genovese, C.R., Behrmann, M., 2001. A functional MRI study of face recognition in patients with prosopagnosia. NeuroReport 12 , 1581-1587.

Mayer, E., Rossion, B., in press. Prosopagnosia. In: Godefroy, O., Bogousslavsky, J. (Eds.). The cognitive neurology of stroke: Cambridge University Press.

Mayer, E., Fistarol, P., Valenza, N., 1999. Prise en charge neuropsychologique d'une patiente prosopagnosique. In: Azouvi, P., Perrier, D., Van der Linden, M. (Eds.), La Reeducation en Neuropsychologie: Etudes de Cas. Solal, Marseille.

McCandliss, B.D., Cohen, L., Dehaene, S., 2003. The visual word form area: expertise for reading in the fusiform gyrus. Trends Cogn. Sci. 7 , 293-299.

McCarthy, M., Puce, A., Gore, J.C., Allison, T., 1997. Face-specific processing in the human fusiform gyrus. J. Cogn. Neurosci. 9, 605-610.

Meadows, J.C., 1974. The anatomical basis of prosopagnosia. J. Neurol. Neurosurg. Psychiatry 37, 489-501.

Michel, F., Poncet, M., Signoret, J.L., 1989. Les lésions responsables de la prosopagnosie sont-elles toujours bilatérales? Rev. Neurol. 145, 764-770.

Milner, A.D., Perrett, D.I., Johnston, R.S., Benson, P.J., Jordan, T.R., Heeley, D.W., Bettucci, D., Mortara, F., Mutani, R., Terazzi, E., 1991. Perception and action in 'visual form agnosia'. Brain 114, 405-428.

Ogawa, S., Lee, T.M., Kay, A.R., Tank, D.W., 1990. Brain magnetic resonance imaging with contrast dependent on blood oxygenation. Proc. Natl. Acad. Sci. U. S. A. 87, 9868-9872.

Oldfield, R.C., 1971. The assessment and analysis of handedness: the Edinburgh inventory. Neuropsychologia 9, 97-113.

Price, C.J., Devlin, J.T., 2003. The myth of the visual word form area. NeuroImage 19, 473-481.

Puce, A., Allison, T., Bentin, S., Gore, J.C., McCarthy, G., 1998. Temporal cortex activation in humans viewing eye and mouth movements. J. Neurosci. 18, 2188-2199.

Quaglino, A., Borelli, G.B., Della Sala, S., Young, A.W., 2003. Quaglino's 1867 case of prosopagnosia. Cortex 39, 440-533.

Rossion, B., Pourtois, G., 2004. Revisiting Snodgrass and Vanderwart's object pictorial set: the role of surface detail in basic-level object recognition. Perception 33, 217-236.

Rossion, B., Dricot, L., Devolder, A., Bodart, J.M., Crommelinck, M., De Gelder, B., Zoontjes, R., 2000. Hemispheric asymmetries for whole-based and part-based face processing in the human fusiform gyrus. J. Cogn. Neurosci. 12, 793-802.
Rossion, B., Schiltz, C., Robaye, L., Pirenne, D., Crommelinck, M., 2001. How does the brain discriminate familiar and unfamiliar faces?: a PET study of face categorical perception. J. Cogn. Neurosci. 13, $1019-1034$.

Rossion, B., Caldara, R., Seghier, M., Schuller, A.-M., Lazeyras, F., Mayer, E., 2003a. A network of occipito-temporal face-sensitive areas besides the right middle fusiform gyrus is necessary for normal face processing. Brain 126, 2381-2395.

Rossion, B., Joyce, C.A., Cottrell, G.W., Tarr, M.J., 2003b. Early lateralization and orientation tuning for face, word, and object processing in the visual cortex. NeuroImage 20, 1609-1624.

Sayres, R., Grill-Spector, K., 2006. Object-selective cortex exhibits performance-independent repetition suppression. J. Neurophysiol. 95, 995-1007.

Schiltz, C., Rossion, B., 2006. Faces are represented holistically in the human occipito-temporal cortex. NeuroImage 32, 1385-1394.

Schiltz, C., Sorger, B., Caldara, R., Ahmed, F., Mayer, E., Goebel, R., Rossion, B., 2006. Impaired face discrimination in acquired prosopagnosia is associated with abnormal response to individual faces in the right middle fusiform gyrus. Cereb. Cortex 16, 574-586.

Schweich, M., Bruyer, R., 1993. Heterogeneity in the cognitive manifestations of prosopagnosia: the study of a group of single cases. Cogn. Neuropsychol. 10, 529-547.

Sereno, M.I., Dale, A.M., Reppas, J.B., Kwong, K.K., Belliveau, J.W., Brady, T.J., Rosen, B.R., Tootell, R.B., 1995. Borders of multiple visual areas in humans revealed by functional magnetic resonance imaging. Science 268, 889-893.

Sergent, J., Signoret, J.-L., 1992. Varieties of functional deficits in prosopagnosia. Cereb. Cortex 2, 375-388.

Sergent, J., Villemure, J.G., 1989. Prosopagnosia in a right hemispherectomized patient. Brain 112, 975-995.

Sergent, J., Otha, S., MacDonald, B., 1992. Functional neuroanatomy of face and object processing. A positron emission tomography study. Brain 115, 15-36.

Sergent, J., MacDonald, B., Zuck, E., 1994. Structural and functional organisation of knowledge about faces and proper names: a positron emission tomography study. In: Umiltà, C., Moscovitch, M. (Eds.), Attention and Performance XV. MIT Press, Cambridge, pp. 203-208.

Schmahmann, J.D., 2004. Disorders of the cerebellum: ataxia, dysmetria of thought, and the cerebellar cognitive affective syndrome. J. Neuropsychiatry Clin. Neurosci. 16, 367-378.

Snodgrass, J.G., Vanderwart, M., 1980. A standardized set of 260 pictures: norms for name agreement, image agreement, familiarity, and visual complexity. J. Exp. Psychol. 6, 174-215.

Steeves, J.K., Culham, J.C., Duchaine, B.C., Pratesi, C.C., Valyear, K.F., Schindler, I., Humphrey, G.K., Milner, A.D., Goodale, M.A., 2006. The fusiform face area is not sufficient for face recognition: evidence from a patient with dense prosopagnosia and no occipital face area. Neuropsychologia 44, 594-609.

Sunaert, S., Van Hecke, P., Marchal, G., Orban, G.A., 1999. Motionresponsive regions of the human brain. Exp. Brain Res. 127, 355-370.

Talairach, G., Tournoux, P., 1988. Co-Planar Stereotaxic Atlas of the Human Brain. Thieme, New York.

Tootell, R.B., Hadjikhani, N., 2001. Where is 'dorsal V4' in human visual cortex? Retinotopic, topographic and functional evidence. Cereb. Cortex $11,298-311$.

Tovee, M.J., 1998. Face processing: getting by with a little help from its friends. Curr. Biol. 8, R317-R320.

Tranel, D., Damasio, A.R., Damasio, H., 1988. Intact recognition of facial expression, gender, and age in patients with impaired recognition of face identity. Neurology 38, 690-696.

Uttner, I., Bliem, H., Danek, A., 2002. Prosopagnosia after unilateral right cerebral infarction. J. Neurol. 249, 933-935.

Wada, Y., Yamamoto, T., 2001. Selective impairment of facial recognition due to a haematoma restricted to the right fusiform and lateral occipital region. J. Neurol. Neurosurg. Psychiatry 71, 254-257. 
Warrington, E., 1984. Warrington Recognition Memory Test. Western Psychological Services, Los Angeles.

Wicker, B., Michel, F., Henaff, A.M., Decety, J., 1998. Brain regions involved in the perception of gaze: a PET study. NeuroImage 8, 221-227.

Wigan, A.L., 1844. A New View of Insanity: The Duality of the Mind. Longman, London.

Wilbrand, H., 1892. Ein Fall von Seelenblindheit und Hemianopsie mit Sectionsbefund. Dtsch. Z. Nervenheilkd. 2, 361-387.

Zangenehpour, S., Chaudhuri, A., 2005. Patchy organization and asym- metric distribution of the neural correlates of face processing in monkey inferotemporal cortex. Curr. Biol. 15, 993-1005.

Zeki, S., 1990. A century of cerebral achromatopsia. Brain 113 (6), $1721-1777$.

Zeki, S., Watson, J.D., Lueck, C.J., Friston, K.J., Kennard, C., Frackowiak, R.S., 1991. A direct demonstration of functional specialization in human visual cortex. J. Neurosci. 11, 641-649.

Zihl, J., Von Cramon, D., 1986. Visual field rehabilitation in the cortically blind? J. Neurol. Neurosurg. Psychiatry 49, 965-966. 